\title{
PRESENT STATUS OF THE ASTRONOMICAL EPHEMERIS*
}

\author{
A.M. Sinzi ${ }^{1)}$, K. Inoue ${ }^{23}$, Y. Kubo ${ }^{2)}$, Sh. Aoki ${ }^{3)}$, \\ H. Kinoshita ${ }^{3)}$ and H. Nakai ${ }^{3)}$
}

Received 1978 September 18

\begin{abstract}
In order to avoid confusion in the future the departure of the fundamental ephemerides, contained in the current volumes of the Astronomical Ephemeris (A.E.), from their basic theories have been investigated by rigorous preparations of computer programs.

Regarding Newcomb's ( $1895 \mathrm{~b}$ ) Tables of the Sun, it is found that several small terms in the perturbations of the radius vector by Venus and Mars have been neglected in the tabular values; besides the remarks by Clemence (1943) and Kinoshita et al. (1974) on the perturbations in the longitude by Venus and Jupiter, respectively. Some of the numerical coefficients in the expression of the equation of the center seem to be in error, which causes an, error of \pm 0 " 01 in the longitude of the Sun. In opposition to the remark by Williams and Clemence (1942) it seems appropriate that Newcomb applied corrections to LeVerrier's values of the eccentricity and the perihelion longitude of the earth's orbit due to the elimination of terms dependent solely on the mean anomaly of the earth, as far as the perturbations in the longitude are concerned. The amount of the lunar inequality in the longitude calculated directly be making use of the daily ephemerides of the Sun and the Moon differs from that given by the Tables by about \pm 0.04 . Although the expressions for the planetary perturbations of the latitude in Newcomb's and LeVerrier's Tables are both based on LeVerrier's (1858) fundamental numbers, these Tables yield values differing by about \pm 0 " 12 from each other.

Comparison bewteen the A.E. and the results of the rigorous computation has been made for the data for 1975 except for those of the Moon for which a comparison by Inoue (1977) for the data from 1952 to 1.980 is available. The main features of the A.E.-data thus obtained are as follows: (a) Sun-Discrepancies from the rigorous computations in the longitude and the radius vectors are caused partly by the differences between the basic expressions and the actual tabular figures in Newcomb's Tables. The remaining discrepancies do not seem still to be caused solely by accumulation of random errors. The discrepancy in the latitude is almost entirely caused by the difference between the basic expressions and the tabular figures. (b) Inner planets - Most of the discrepancies in the heliocentric coordinates can be regarded as tolerable, except that the radius vector of Mercury in the A.E. is systematically smaller than the values obtained by the rigorous computation. The effect of the discrepancies in the solar coordinates appear significantly in the geocentric ephemerides. (c) Outer planets - The numerical integrations by Eckert, Brouwer and Clemence (1951) are admirably correct. The right ascensions and declinations in the A.E. suffer from the incompleteness of the correction due to the change in the value of the aberration

* The excerpt of this paper was read at the IAU Symposium No. 81 in May 1978 and has been published in Dynamics of the Solar System, Proceedings of the IAU Symposium No. 81, Ed. R.L. Duncombe, D. Reidel Pub. Co., 1979.

1) Hydrographic Department 2) Astronomical Division 3) Tokyo Astronomical Observatory
\end{abstract}


constant. The geocentric distances of Uranus and Neptune in the A.E. seem to be those obtained by omitting the figures lower than the printed last decimals. (d) Moon-The computation accuarcies of the A.E. may be around \pm 0 " 0010 for the longitude, \pm 0 " 003 for the latitude and $\pm 0.6 \times$ $10^{-6}$ for the horizontal parallax. Errors in the A.E. may be caused mostly by the incomplete treatment of the higher terms regarding the change in the value of the dynamical form factor of the earth.

Although the amounts of the discrepancies surveyed in the present investigation might be regarded as permissible in the past, we can now compute the ephemerides as precisely as we want whenever the basic theory is rigidly specified, with the general availability of computers. For example, the $j=2$ ephemeris of the Moon prepared by Inoue (1977) satisfactorily agrees with the Fundamental Lunar Ephemeris (Van Flandern, 1976) of the U.S. Nautical Almanac Office, the discrepancies betwen them being \pm 0 " 0002 in the longitude and latitude and $\pm 2^{\prime \prime} \times 10^{-6}$ in the horizontal parallax. Hence, we consider that the international ephemerides in the future should be computed by at least two institutes independently using different types of computer.

Key words: Tables of the Sun - fundamental ephemerides

\section{Introduction}

The IAU (1976) System of Astronomical Constants and a new set of the fundamental theories will expectedly be introduced into the international and national ephemerides for the volumes of 1984 onwards. In order to avoid any confusion in the future, it is necessary to clarify characters of the data published in the current volumes of the Astronomical Ephemeris=American Ephemeris, both abbreviated as A.E., in the reference to the basic theories. With this end in view, computer programs for the calculations of the ephemerides of the Sun and the inner planets based on Newcomb's (1895b, c, d, 1898) Tables have been prepared at Tokyo Astronomical Observatory (TAO) and Hydrographic Department of Japan (JHD) independently of each other using different types of computer and hence different types of FORTRAN. The JHD (Inoue, 1977) has further prepared the programs for the Moon's ephemerides based on Brown-Eckert theory, and has reproduced Eckert, Brouwer and Clemence's (1951) numerical integrations of the outer planets. Fundamental ephemerides thus computed are compared in the present paper with those data tabulated in the current volumes of the A.E.

Computers used at the TAO and JHD for preparing all the ephemerides referred to in the present paper are FACOM $230-58$ and NEAC $2200 / 500$, respectively. FACOM 230-58 has main memory size of $768 \mathrm{~KB}$ and its word length is $32 \mathrm{bits,}$ while the memory size of NEAC $2200 / 500$ is $256 \mathrm{~KB}$ and its one word consists of 48 bits.

\section{Sun}

\subsection{Remarks on Newcomb's Tables of the Sun}

In the Introduction (pp. 9-20) of Newcomb's Tables of the Motion of the Earth on its Axis and around the Sun (hereafter called Tables whenever confusion may not occur with LeVerrier's Tables) he gives the basic data and formulas (hereafter called basis) which. were employed to calculated the individual values in the main body (called tabulation or tabular values) of the Tables. Williams and Clemence (1942) briefly annotated that the orbital elements of the earth in the basis (pp. 9, 10) are exactly consistent with those given in Newcomb's (1895a) Astronomical Constants. In fact the elements 
for 1900 in the basis can be derived from "concluded" elements for 1850, their secular variations and the precessions for 1850 presented in Astronomical Constants (pp. 182, 186, 196). In deriving the concluded elements from those adopted in LeVerrier's (1858) Tables generales du mouvement du soleil, Newcomb (Astronomical Constants, p. 180) applied the corrections +0.054 and +1.4 respectively to the values of the eccentricity and the longitude of perihelion in such a way to eliminate those terms in the perturbations in the longitude which depend solely upon the position of the earth having the same period as the earth's motion. Such terms can be written:

or

$$
\delta \lambda=C \cos g+S \sin g
$$

$$
\delta \lambda=M \sin L+N \cos L
$$

where $\lambda, g$ and $L$ stand for the true longitude, mean anomaly and mean longitude of the earth, respectively. In such a case a term in the form of

$$
\delta R=\frac{S}{2} \cos g-\frac{C}{2} \sin g
$$

or

$$
\delta R=-\frac{N}{2} \sin L+\frac{M}{2} \cos L
$$

need to be added to the perturbations in the radius vector so as to compensate the effect due to the modification of the value of the eccentricity (LeVerrier, 1856, p. 39).

Williams and Clmence (1942) remarked that Newcomb's procedure in this regard was erroneous because (i) LeVerrier had already excluded the terms of (1)' in the perturbations of longitude in his Tables $d u$ soleil and (ii) Newcomb neglected in his Tables not only the compensation terms of (2) in the radius vector but also the terms in the form of $A \cos g+B \sin g$ which intrincically existed in the perturbations of the radius. vector. In fact, after the presentation of the list of figures of the perturbation terms, LeVerrier (1858, p. 38) stated that the exclusion of the terms of $(1)^{\prime}$ and the addition of the terms of $(2)^{\prime}$ should be made in the practical calculation, presenting the actual

\begin{tabular}{|c|c|c|c|c|}
\hline & $\begin{array}{l}M \\
0\end{array}$ & ${ }_{1}^{N}$ & $\begin{array}{l}\text { Longitude: } \\
\text { Exclusion of term } \\
M \sin L+N \cos L\end{array}$ & $\begin{array}{c}\text { Radius yector: } \\
\text { Inclusion of } \\
\text { compensation term } \\
-(N / 2) \sin L+(M / 2) \cos L\end{array}$ \\
\hline Mercury & +2 & -8 & no (Tab. XIII) & yes? (Tab. XXXIV) \\
\hline Venus & -4 & -35 & no (Tab. XXII) & yes (Tab. XXXVI) \\
\hline Mars & -12 & -8 & no (Tab. XXVIII) & yes (Tab. XXXVIII) \\
\hline Jupiter & -53 & -47 & no (Tab. XXX) & yes (Tab. XL) \\
\hline Saturn & 0 & 0 & - & - \\
\hline Sum & -67 & -98 & & \\
\hline
\end{tabular}
figures of their coefficients. However, LeVerrier's Tables seem also internally inconsistent in this respect. Result of a test calculation of the relevant tables in his Tables is

Table 1 Amendment of perturbation performed in LeVerrier's Tables du soleil 
given in Table 1. Actually the terms of $(1)^{\prime}$ remain in the tables of the perturbation whereas the terms of $(2)^{\prime}$ are also included.

Newcomb (Astronomical Constants, p. 6) had compared observation with his provisional tables reconstructed from LeVerrier's Tables for the data previous to 1864 and with the A.E. for the data after 1864. According to Williams and Clemence (1942) Newcomb's provisional tables include the terms of (1). The A.E. had been based on LeVerrier's Tables du soleil for the volumes after 1864. Consequently we may esteem it as an appropriate procedure that Newcomb applied the corrections +0."054 and +1" 4 respectively to LeVerrier's values of the eccentricity and the perihelion longitude as far as the perturbation in the longitude is concerned.

History of the values of the eccentricity of the earth's orbit can be summarized as follows :

\begin{tabular}{|c|c|c|c|}
\hline & epoch & & \\
\hline $\begin{aligned} e & =0.016770464 \\
& =\left(3459^{\prime \prime} .1565\right)\end{aligned}$ & 1850 & LeVerrier's & provisional value $(1858$, p. 53$)$ \\
\hline+0.12 & & " & corr. from obs. (ibid. p. 97) \\
\hline 3459.28 & 1850 & " & adopted value in Tables (ibid. p. 102) \\
\hline+0.054 & & Newcomb's & corr. due to (1) (Astr. Const. p. 180) \\
\hline+0.12 & & :" & corr. from obs. (ibid. p. 96) \\
\hline 3459.454 & 1850 & " & concluded value (ibid. p.182) \\
\hline$(-4.304)$ & & $"$ & secular variation (ibid. p. 186) \\
\hline 3455.150 & 1900 & $\because \prime \prime$ & adopted value in Tables (p.9) \\
\hline
\end{tabular}

The figures in parentheses are not given explicitly in the original materials.

Note 1.-Table XXXVIII of LeVerrier's Tables for the perturbations in the radius vector by Mars lacks the modification due to the change in the adopted mass of Mars, while in the other tables of the perturbations by Venus and Mars the tabular figures have been respectively multiplied by the factors 1.004 for Venus and 0.895 for Mars, excepting Tables XXII and XXXVI for which the effects due to the modification is almost insignificant.

Note 2.-In LeVerrier's Tables the values of the coefficients of higher terms in the expansion formulas of the equation of the center and the radius vector presented on pp. 102 and 103 are not consistent with his adopted value of the eccentricity and might have been taken from those (LeVerrier, 1858, p. 53) based on the provisional value of the eccentricity. The tabular values of the equation of the center (Table VII) and the radius vector (Table XXII) are consistent with the expansion formulas on pp. 102 and 103, respectively.

In the basis ( $\mathrm{p} .10)$ of Newcomb's Tables, the series expansions of the equation of the center and the logarithm of the radius vector are presented. When we simply apply the Kepler's equation, the coefficients of the expression of the logarithm of the radius vector are practically consistent with the adopted value of the eccentricity in the basis (p.9), while in the expression of the equation of the center there appears a discrepancy by about $\left(0^{\prime \prime} 004+0 \prime 007 T\right) \sin 3 g$ as can be found by comparison of the following each pair of formulas. 


$$
\begin{aligned}
& \begin{aligned}
& v-g= \begin{array}{c}
g\left(6910.057-17.240 T-0.052 T^{2}\right) \\
6910.057-17.2419-0.0520
\end{array} \\
&+\sin 2 g\left(\begin{array}{l}
72.338-0.361 T \\
72.3393-0.3610-0.001
\end{array} T^{2}\right) \\
&+\sin 3 g\left(\begin{array}{l}
1.054-0.001 T) \\
1.0501-0.0079
\end{array}\right) \\
&+\sin 4 g\left(\begin{array}{ll}
0.018 \\
0.0174
\end{array}\right)
\end{aligned} \\
& \log R \times 10^{8}=\quad 3057-15 T^{T} \\
& 3056.6-15.2 \\
& \begin{array}{r}
+\cos g\left(-727412+1814 T+5 T^{2}\right) \\
-727411.9+1814.8+5.8
\end{array} \\
& +\cos 2 g(-9138+46 T) \\
& \text { - } 9138.1+45.6 \\
& +\cos 3 g(-\quad 145+144.5+1.1 \\
& +\cos 4 g(-\quad 2)
\end{aligned}
$$

$(4),(4)^{\prime}$

The figures in each upper rank assigned as (3) and (4) are those given in the basis, and the figures in each lower rank in italic style assigned as $(3)^{\prime}$ and $(4)^{\prime}$ are those obtained from the Kepler's equation. No further terms affect the values down to the third decimal places for the equation of the center and eighth places for the logarithm of the radius vector.

Clemence (1943) pointed out that Newcomb had not used some terms listed in Table B of the basis to contsruct Tables VIII and XII regarding the perturbation in the longitude by Venus but had purposely adopted other terms which are given in the column "Tables VIII and XII" in Table I of the Clemence's paper, although he could not find the ground of these terms.

Kinoshita et al. (1974) reconstructed Tables VII to XI pertaining to the perturbations in the longitude by making use of Tables $\mathrm{A}$ to $\mathrm{F}$ in the basis and compared with respective tabular values of the Tables. The main features are as follows: (i) For the perturbations by Mercury (Table VII) and Saturn (Table XI) the discrepancies by \pm 1 in the last decimal place of the Tables, 0.01 , appear to distribute at random with small frequency of occurence, suggesting that these discrepancies are caused by rounding-off. (ii) Clemence's remark on the perturbations by Venus referred to above is concretely verified in Table VIII. Residuals after applying the correction for this effect show almost random distribution of \pm 1 , remaining discrepancies reaching to \pm 3 in very restricted portions. (iii) The tabulations for the perturbations by Jupiter (Table X) might have been constructed as if each value for $j=5$ were situated upwards by one rank in Table D. (iv) Discrepancies for the perturbations by Mars (Table IX) might be caused by some'situation like that for Venus in Table VIII and for Jupiter in Table X.

All tabulations of the Tables excepting those pertaining to the arguments, precession and nutation have been recalculated at the JHD being based on the data in the basis. Results of comparison of the calculated values with the respective tabulations are illustrated in Figures 1 to 24 except for Table XXXI, and are summarized in Table 2 to 
which the following remarks on some tables are supplemented.

Table VIII : Systematic discrepancy is due to the effect remarked by Clemence referred to above.

Table X: Systematic discrepancy is due to the effect remarked by Kinoshita et al. referred to aboue. Distribution of the residuals after applying the correction for this effect does not still seem completely random. See Figure $4^{\prime}$.

Tables XII to XV: Although discrepancies appearing in these small tables are of neglegible amount, they may contain the same effect as appears in Tables XXII to XXV. Table XVIII: When we neglect the smallest four terms $4 \cos \left(90^{\circ}+2 g^{\prime}\right), 4 \cos \left(166^{\circ}+7 g^{\prime}\right.$ $-9 g), 4 \cos \left(135^{\circ}+7 g^{\prime}-10 g\right)$ and $4 \cos \left(256^{\circ}+9 g^{\prime}-10 g\right)$ in Table B of the basis, the discrepancy from the tabulation becomes almost random. See Figure $12^{\prime}$.

Table XIX: When we neglect the smallest two terms $3 \cos \left(108^{\circ}-5 g^{\prime}+2 g\right)$ and $4 \cos \left(153^{\circ}\right.$ $\left.-17 g^{\prime}+10 g\right)$ in Table C, the discrepancy from tabulation becomes almost random. See Figure $13^{\prime}$.

Tables XX and XXI : Distributions of discrepancies in these tables may be of random character. When we neglect the smallest terms $3 \cos \left(252^{\circ}-5 g^{\prime}+5 g\right)$ in Table D and $4 \cos \left(194^{\circ}-4 g^{\prime}+2 g\right)$ and/or $3 \cos \left(198^{\circ}-2 g^{\prime}+3 g\right)$ in Table E, the discrepancies from the respective tabulations become larger with systematic distributions.

Tables XXII to XXV: Occurence of discrepancies by \pm 2 suggests that they are not of purely random character. In some portions of Table XXV of single argument, values differing by 2 are tabulated against same values of the argument. Hence the discrepancies in these small tables may be caused by some property of the calculation scheme adopted by Newcomb which might have been applied also to the construction of Tables $\mathrm{XII}$ to XV and XXX.

Table XXVII: The tabular values are rather closer to those derived from the Kepler's equation than those calculated by the formula (4) presented in the basis.

Table XXVIII : The tabular values seem to be biased with periods of $g^{\prime}-3 g$ and $3 g^{\prime}+$ $4 g$.

Table XXXI: In this critical table of very small size, there are insignificant discrepancies in the argument $B$ at four places due to the rounding, i.e. $B=79.47$ for the tabular value of $80,192.45$ for $193,259.48$ for 260 and 291.76 for 291.

For the calculation of the periodic perturbations using Tables $\mathrm{A}$ to $\mathrm{F}$ of the basis, the formula $v_{c} \cos \left(i g^{\prime}+i g\right)+v_{s} \sin \left(j g^{\prime}+i g\right)$ has been employed instead of the formula $s \cos \left(K-j g^{\prime}-i g\right)$ which was adopted by Newcomb to construct the tabulations. We shall call the calculation scheme by the former formula as $V C S$ and that by the latter as $S K$. The discrepancy in the values calculated through $S K$ and VCS is due to the actual difference between the listed values of $s$ and $\sqrt{v_{c}{ }^{2}+v_{s}{ }^{2}}$ in Tables $A$ to $F$ of the basis,

In some of Figures 1 to 24 , singular discrepancies appear vertically against some specific horizontal argument $g$, exhibiting different behaviour from the general pattern of the discrepancy in the adjacent portions. These discrepancies are probably due to the error in the values of

$$
\sum s \cos \left\{K-\left(j n_{1}+i n\right) t\right\} \quad \text { or } \sum s \sin \left\{K-\left(j n_{1}+i n\right) t\right\}
$$


Table 2. Feature of individual tables in Newcomb's Tables of the Sun

\begin{tabular}{|c|c|c|c|c|c|}
\hline Table & content & basis & $\begin{array}{l}\text { discrepanoy } \\
(\text { Table - basis })\end{array}$ & $\begin{array}{l}\text { feature of } \\
\text { discrepancy }\end{array}$ & Flgure \\
\hline & $\begin{array}{l}\text { Longitude } \\
\text { perturbations by }\end{array}$ & & & & \\
\hline $\begin{array}{l}\text { VII } \\
\text { VIII } \\
\text { IX } \\
X \\
X I \\
X I I \\
\text { XIII } \\
X I V \\
X V\end{array}$ & $\begin{array}{l}\text { Mercury } \\
\text { Venus } \\
\text { Mars } \\
\text { Jupiter } \\
\text { Saturn } \\
\text { Venus } \\
\text { Moon } \\
\text { Moon } \\
\text { Moon }\end{array}$ & $\begin{array}{l}\text { Tab. A } \\
\text { Tab. B } \\
\text { Tab. C } \\
\text { Tab. D } \\
\text { Tab. E } \\
\text { Tab. B } \\
\text { p. } 18 \\
\text { p. } 18 \\
\text { p. } 18\end{array}$ & $\begin{array}{l} \pm 1 \\
\pm 7 \\
\pm \\
\pm 5 \\
\pm \\
\pm 1 \\
\pm \\
\pm 1 \\
\pm 1 \\
\pm 1 \\
\pm 1 \\
\pm 1\end{array}$ & $\begin{array}{l}\text { systematic } \\
\text { systematic? } \\
\text { systematic }\end{array}$ & $\begin{array}{l}1 \\
2,2 \\
3 \\
4,4 \\
5 \\
8 \\
6 \\
? \\
9\end{array}$ \\
\hline$X V$ & eq. of center & & & & \\
\hline \multirow[t]{2}{*}{ XVII } & $\begin{array}{l}\text { sec. var. } \\
\text { principai part }\end{array}$ & $\begin{array}{l}\text { p. } 10 \\
\text { p. } 10\end{array}$ & \pm 1 & & $\begin{array}{l}10 \\
11\end{array}$ \\
\hline & $\begin{array}{l}\text { Log. radius vector } \\
\text { perturbations by }\end{array}$ & & 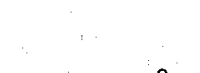 & & \\
\hline $\begin{array}{l}-- \\
X V I I I \\
X I X \\
X X \\
X X I \\
X X I I \\
X X I I I \\
X X I V \\
X X V\end{array}$ & $\begin{array}{l}\text { Mercury } \\
\text { Venus } \\
\text { Mars } \\
\text { Jupiter } \\
\text { Saturn } \\
\text { Venus } \\
\text { Moon } \\
\text { Moon } \\
\text { Moon }\end{array}$ & $\begin{array}{l}\text { Tab. A } \\
\text { Tab, B } \\
\text { Tab, C } \\
\text { Tab, D } \\
\text { Tab. E } \\
\text { Tab, B } \\
\text { p. } 18 \\
\text { p. } 18 \\
\text { p. } 18\end{array}$ & $\begin{array}{l}( \pm 6) \times 10^{-8} \\
\pm 3 \\
\pm 3: \\
\pm 1 \\
\pm 1 \\
\pm 1 \\
\pm 2 \\
\pm 1 \\
\pm 2\end{array}$ & $\begin{array}{c}\text { ( no table) } \\
\text { systemattc } \\
\text { systemattc } \\
\vdots \\
\vdots\end{array}$ & $\begin{array}{l}- \\
12,12 \\
13,13^{\prime} \\
14 \\
15 \\
18 \\
16 \\
17 \\
19\end{array}$ \\
\hline & elliptical terms & & & & \\
\hline $\begin{array}{l}X X V I \\
X X V I I\end{array}$ & $\begin{array}{l}\text { sec. var. } \\
\text { principal part }\end{array}$ & $\begin{array}{l}\text { p. } 10 \\
\text { p. } 10\end{array}$ & \pm 1 & systematic? & $\begin{array}{l}20 \\
21\end{array}$ \\
\hline \multirow[b]{2}{*}{$\begin{array}{l}X X V I I I \\
\overline{X X I X} \\
\overline{X X X} \\
X X X I\end{array}$} & $\begin{array}{l}\text { Lat1 tude } \\
\text { perturbations by }\end{array}$ & & & & \\
\hline & $\begin{array}{l}\text { Venus } \\
\text { Mars } \\
\text { Jupiter } \\
\text { Saturn } \\
\text { Moon } \\
\text { Moon }\end{array}$ & $\begin{array}{l}\text { Tab, F } \\
\text { Tab, F } \\
\text { Tab, F } \\
\text { Tab, F } \\
\text { p. } 18 \\
\text { p. } 18\end{array}$ & $\begin{array}{l} \pm 1 \\
( \pm 2) \times 0.01 \\
\pm 1 \\
( \pm 1) \\
\pm 1 \\
\pm 0\end{array}$ & $\begin{array}{l}\text { systematic? } \\
\text { (no table) } \\
\text { (no table) }\end{array}$ & $\begin{array}{l}22 \\
\overline{23} \\
24 \\
--\end{array}$ \\
\hline
\end{tabular}

* Fygure in parentheses is the maximum value of the perturbations given by the basis . Flgure with colon(:) denotes that discrepancles larger than the flgure rarely appear.

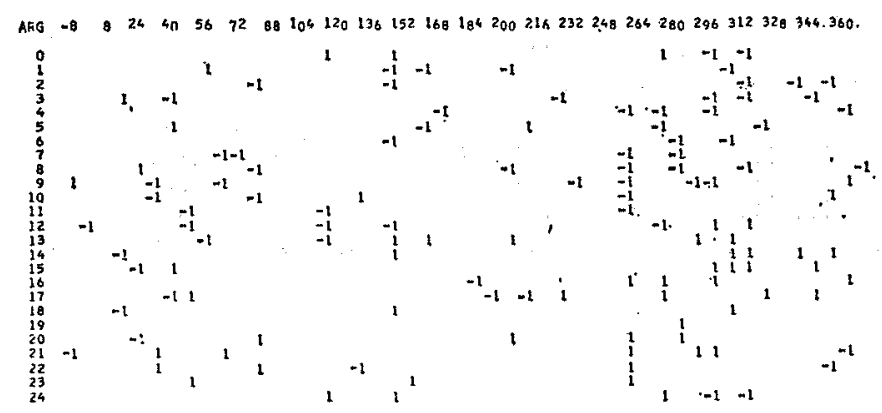

Figure 1. Table VI-basis; vert. arg. I, hor. arg. $g$ 

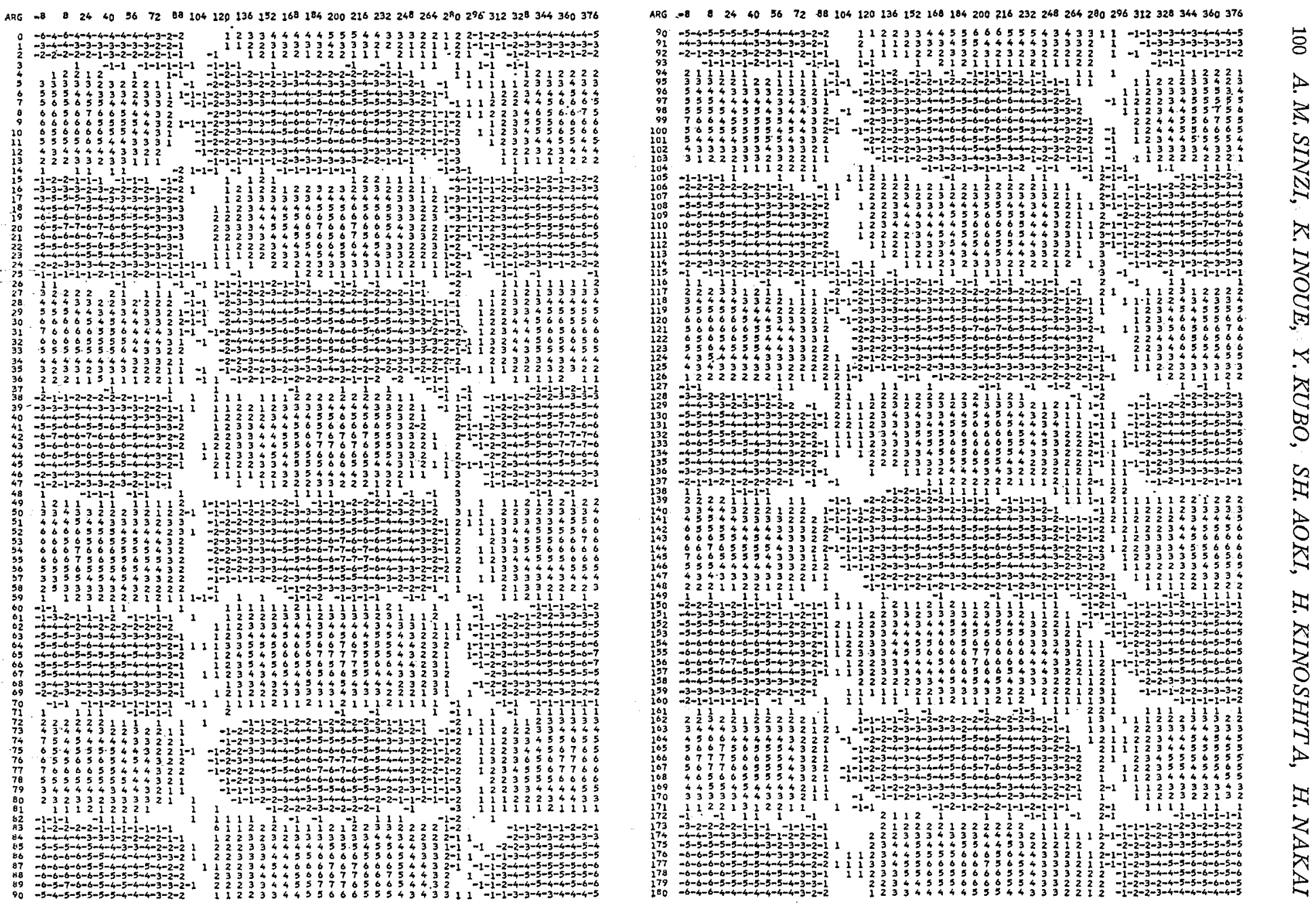

Figure 2. Table VIII-basis; vert. arg. II, hor. arg. g, cf. Figure 2' on p. 103 

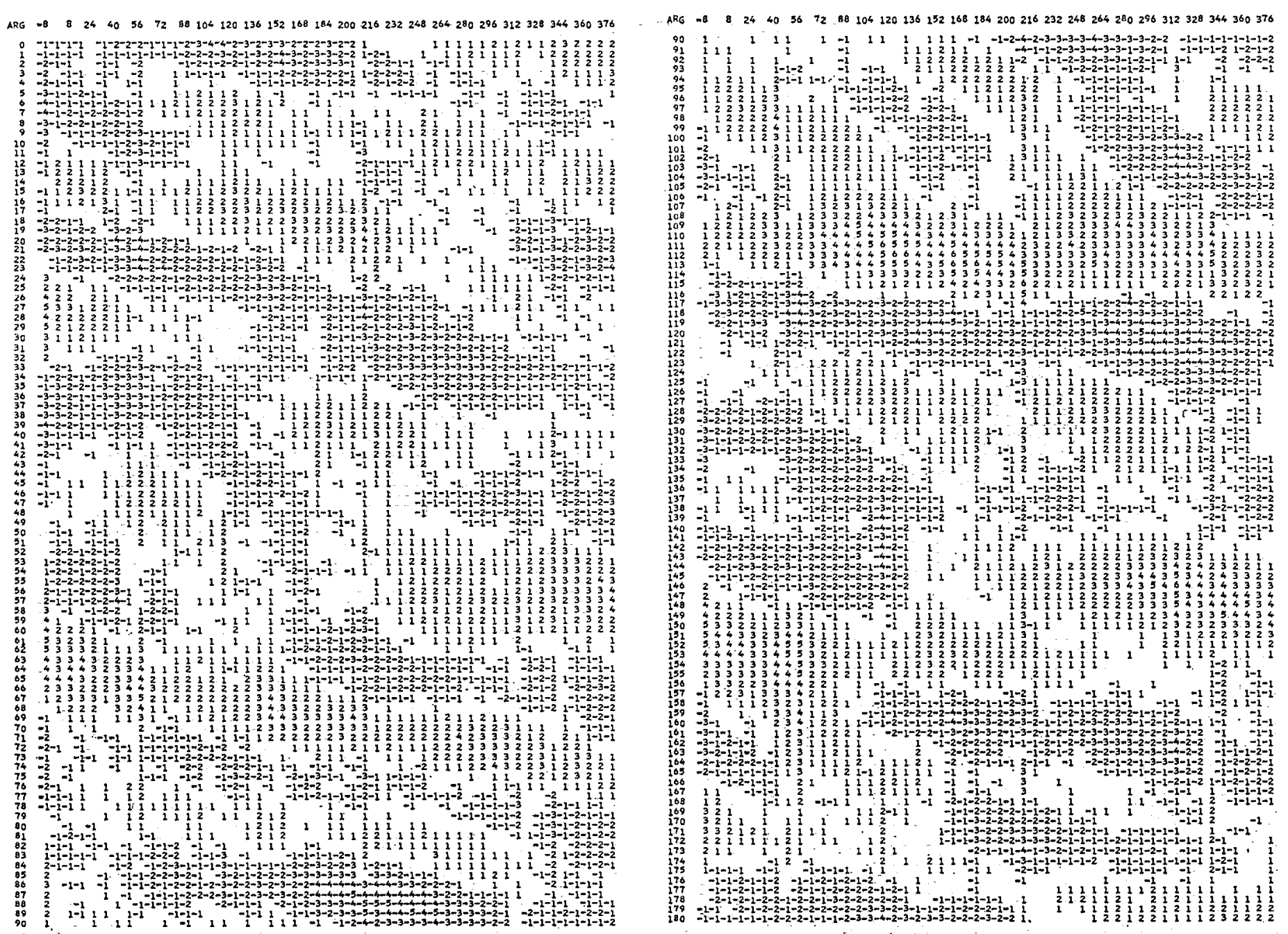

Figure 3. Table IX-basis; vert. arg. III, hor arg. $g$ 
102 A. M. SINZI, K. INOUE, Y. KUBO, SH. AOKI, H. KINOSHITA, H. NAKAI

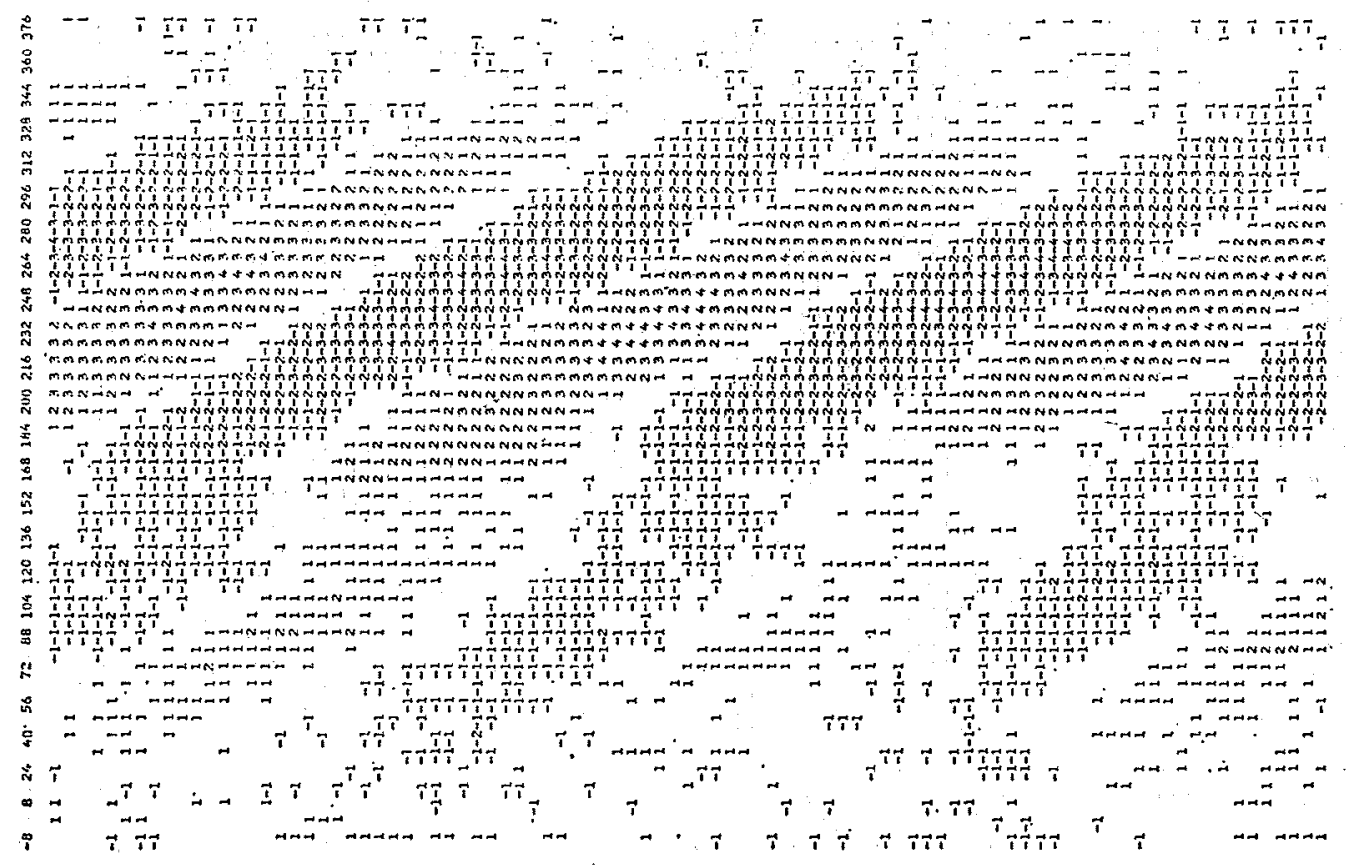

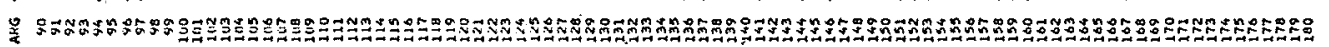

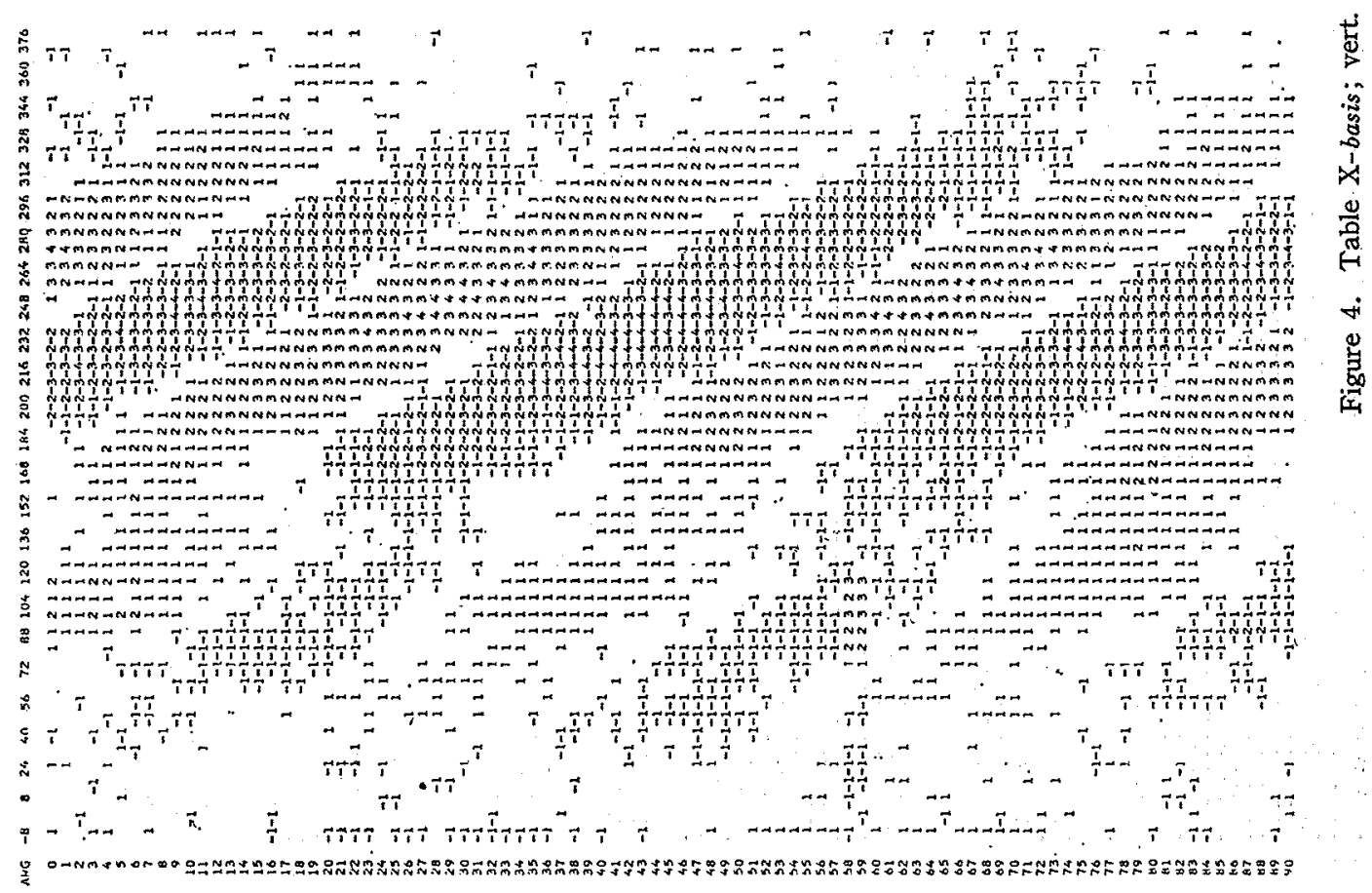




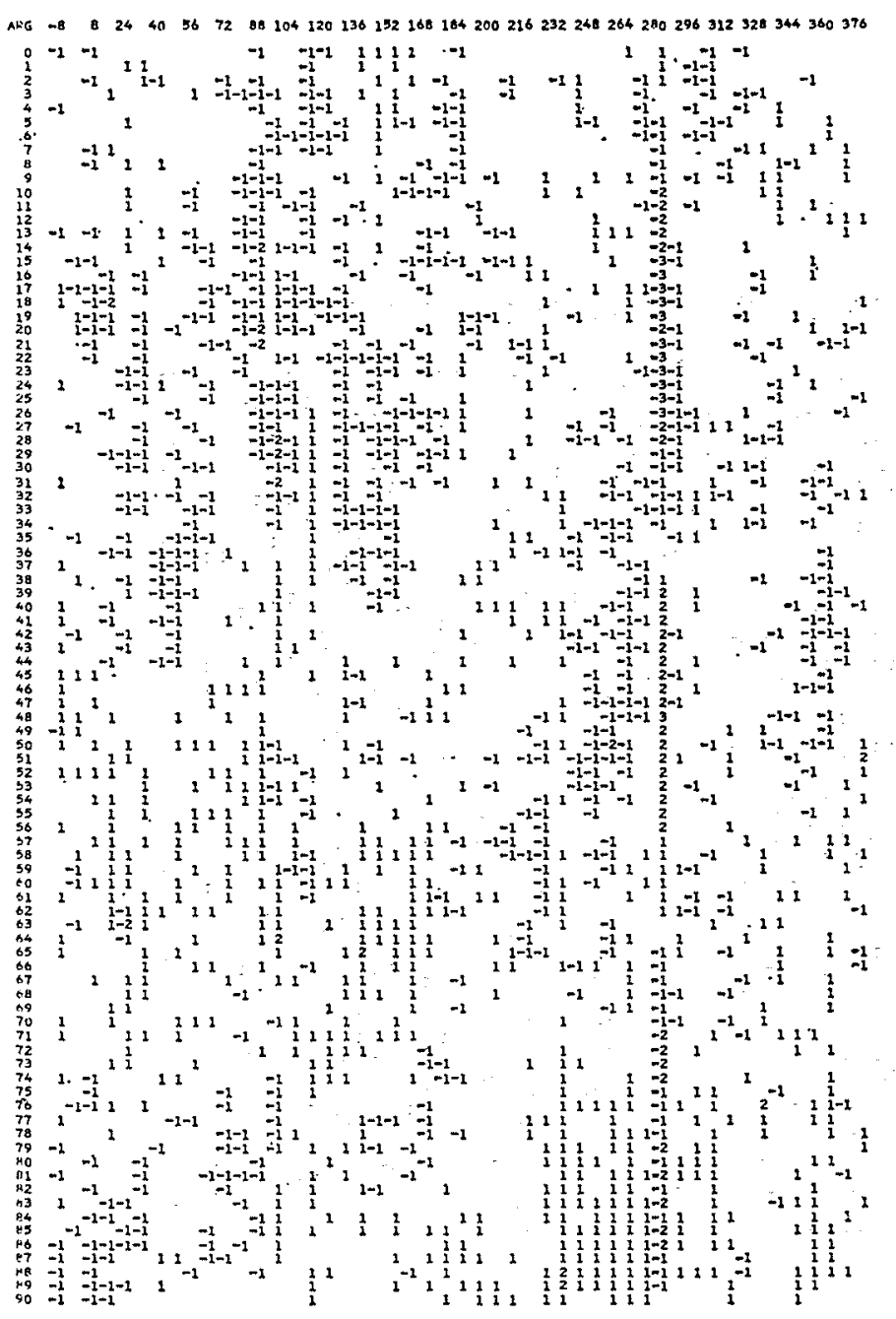

Figure 2; Table VIII-basis amended by Clemence's remark

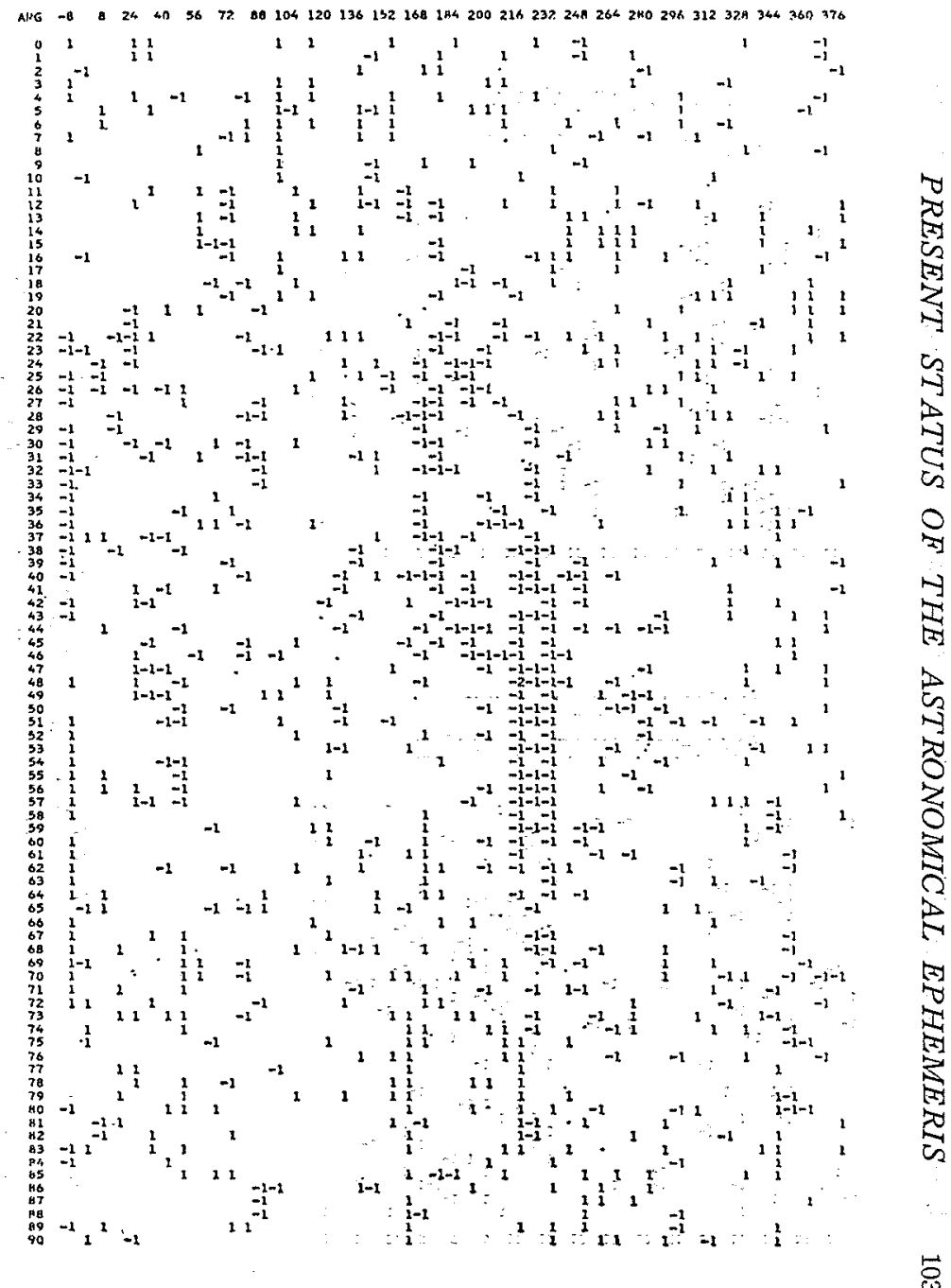

Figure 4?. Table $\mathrm{X}$-basis amended by Kinoshita et al's remark 
104 A.M. SINZI, K.INOUE, Y. KUBO, SH. AOKI, H. KINOSHITA, H. NAKAI
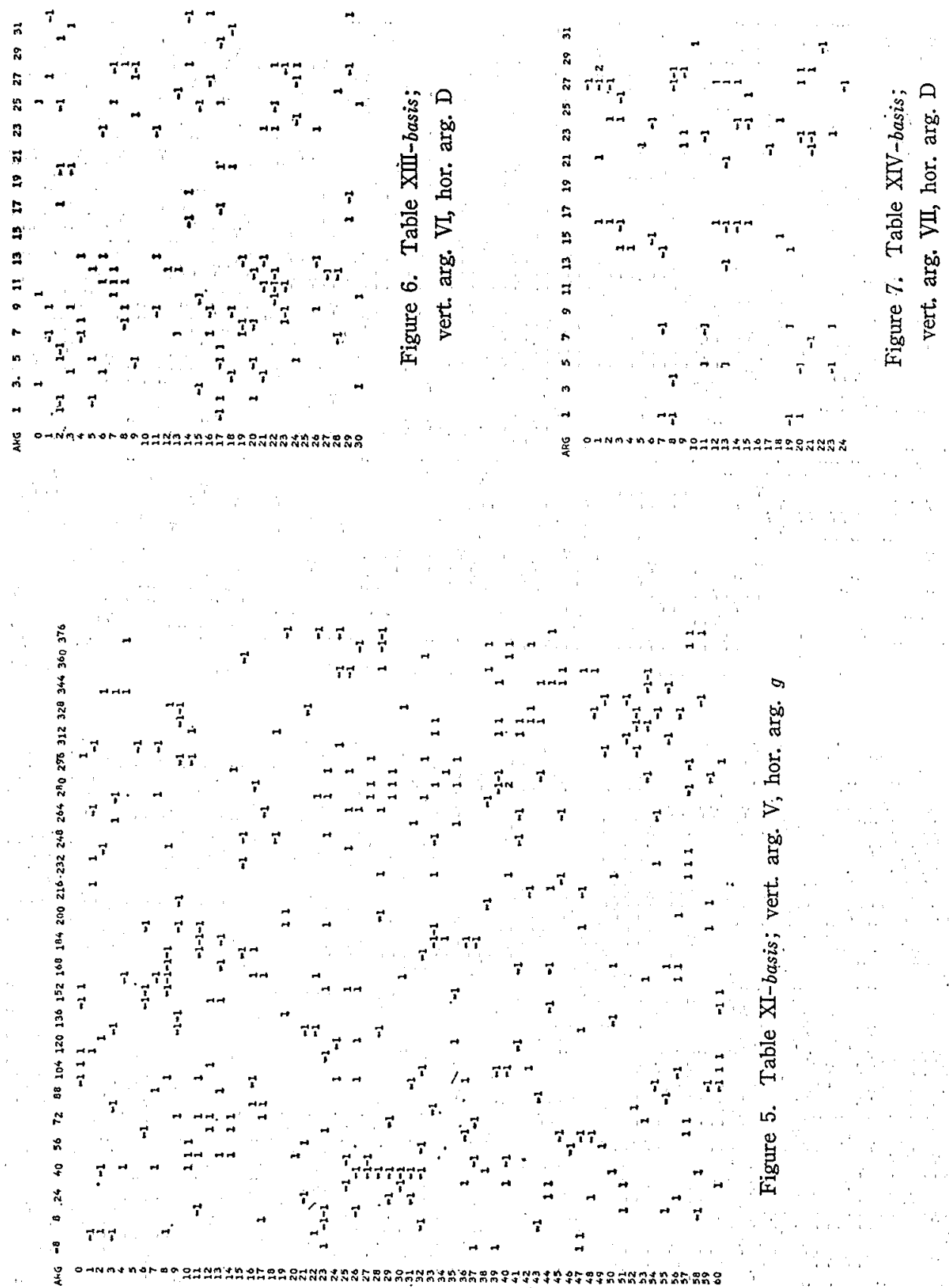

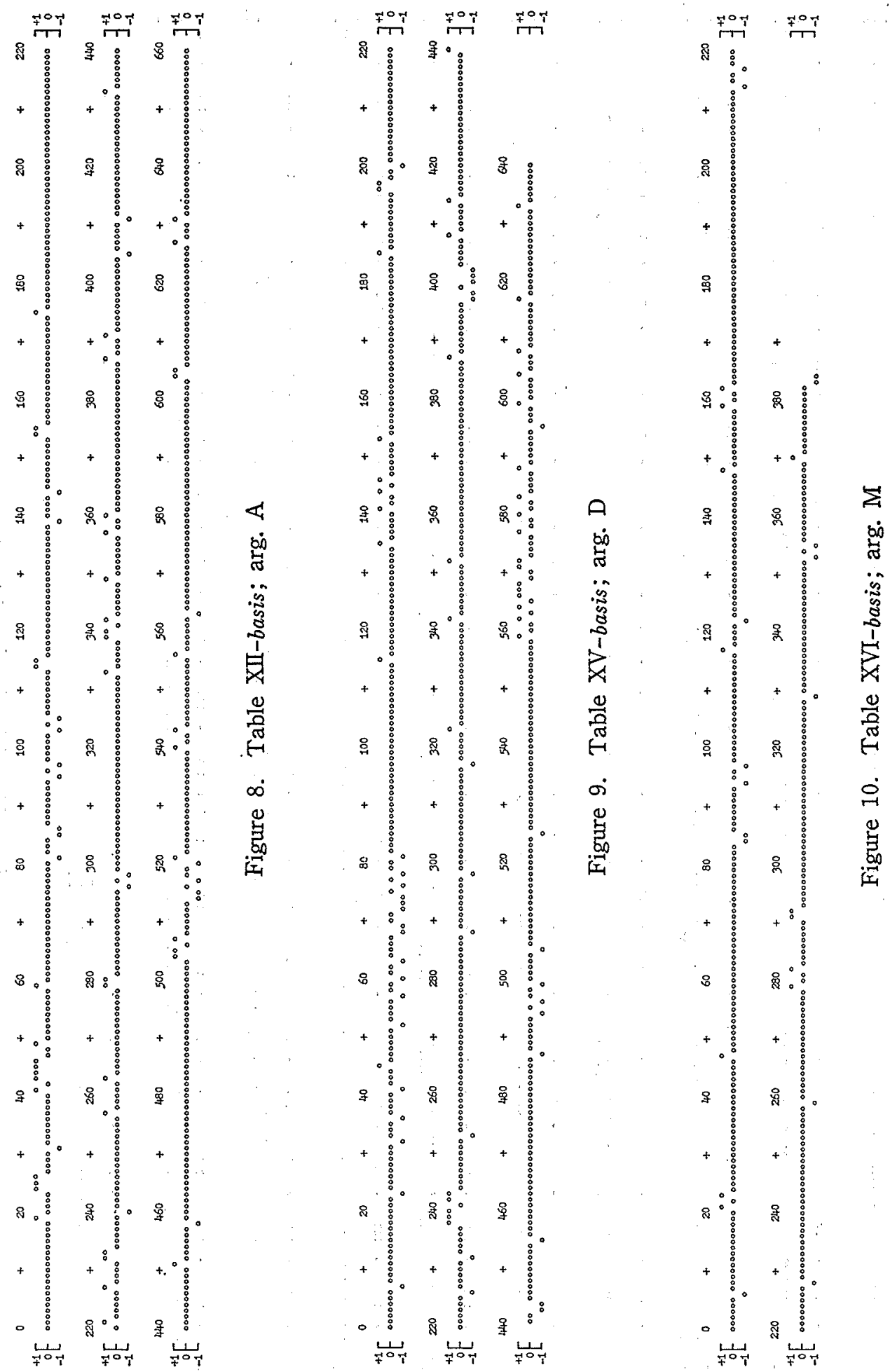

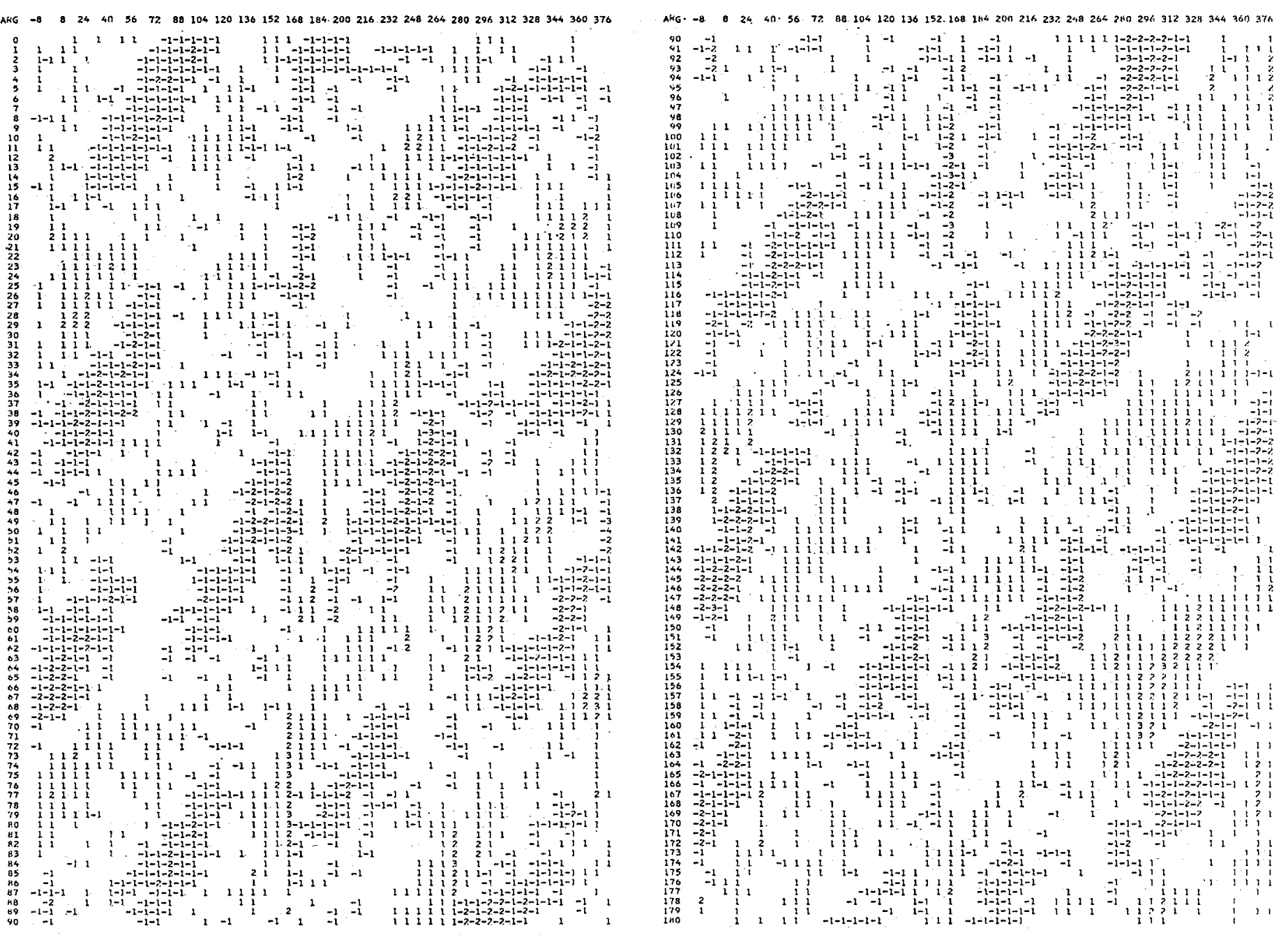

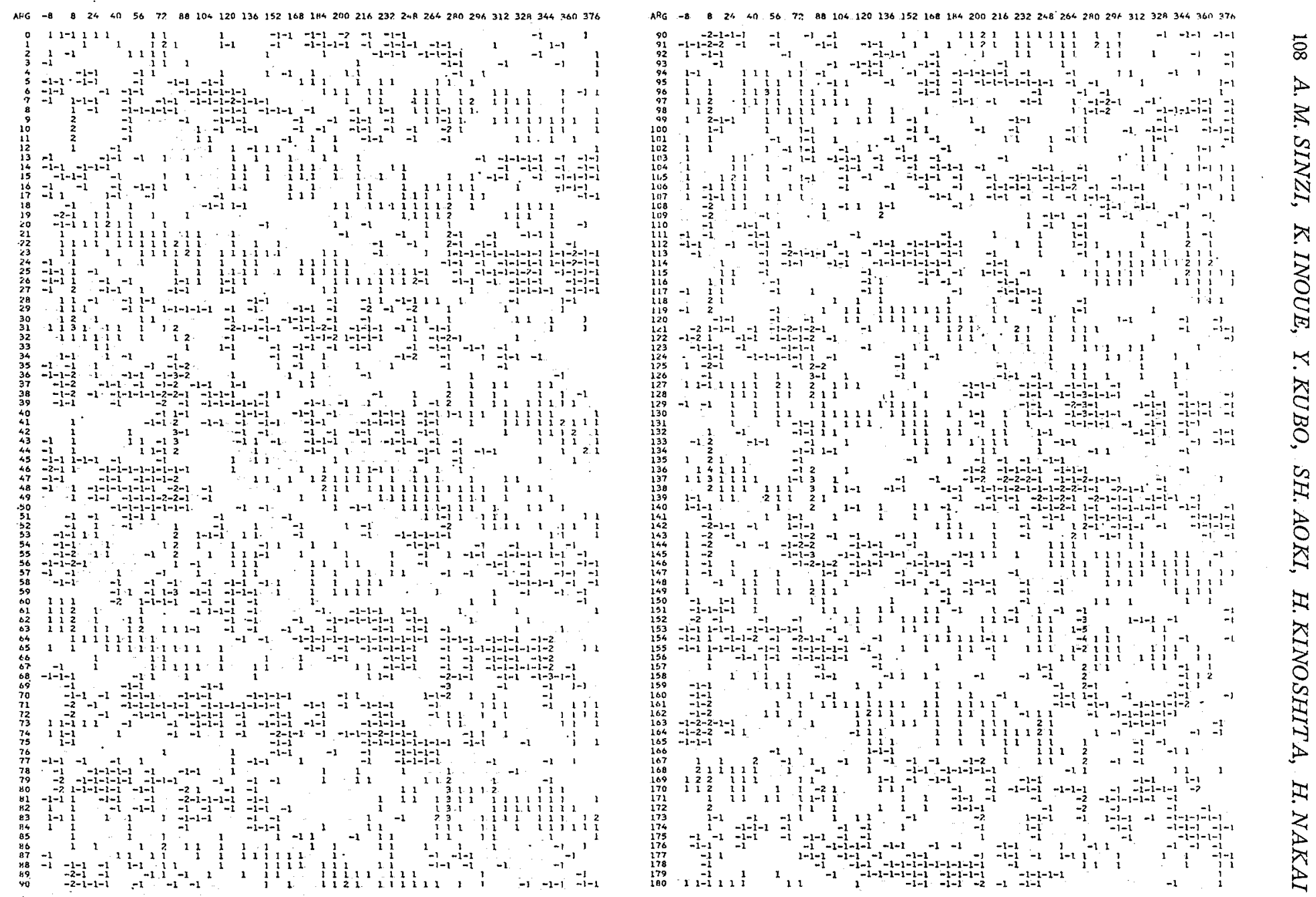

Figure 13. Table XIX-basis; vert. arg. III, hor.' arg. g, cf. Figure $13^{\prime}$ 

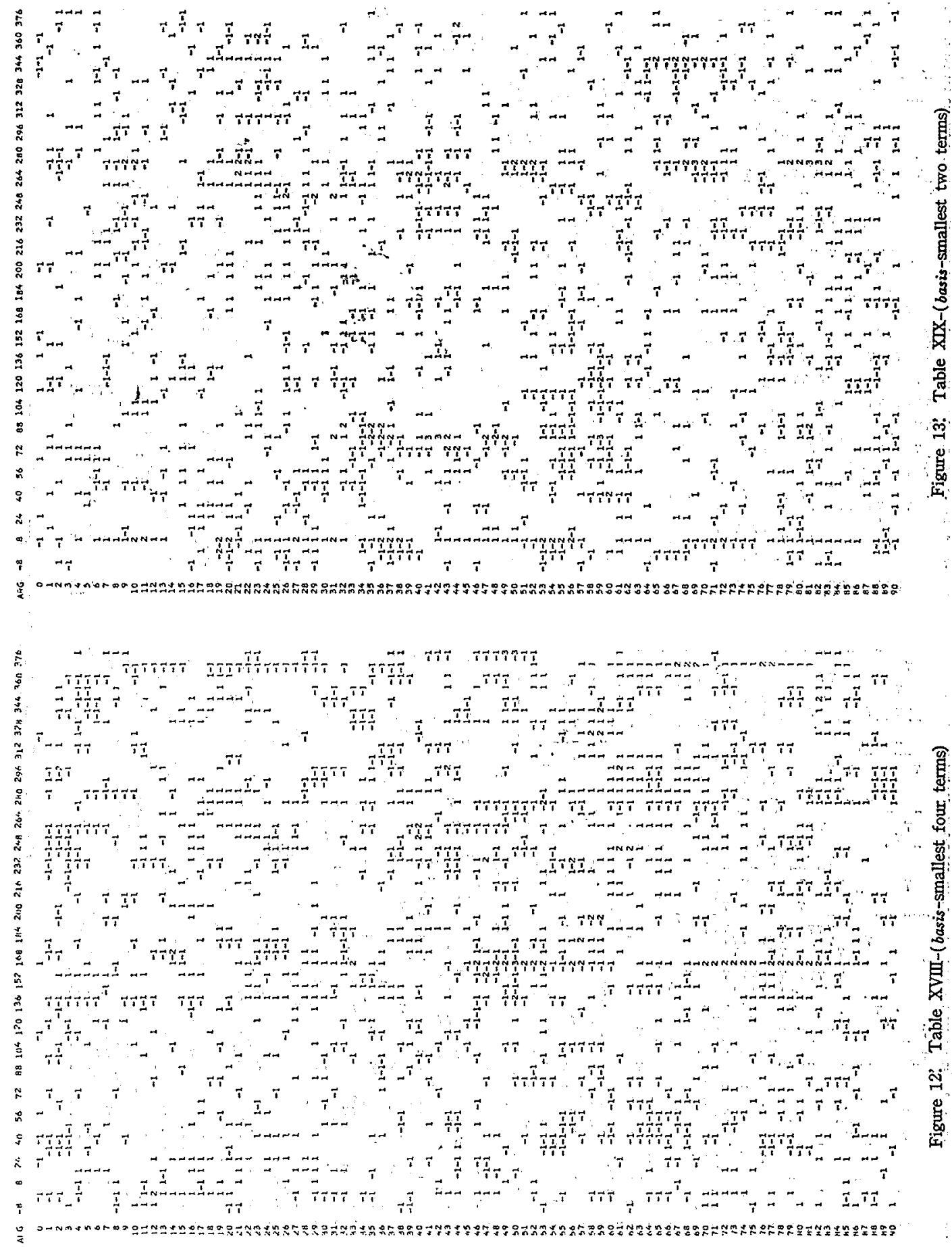

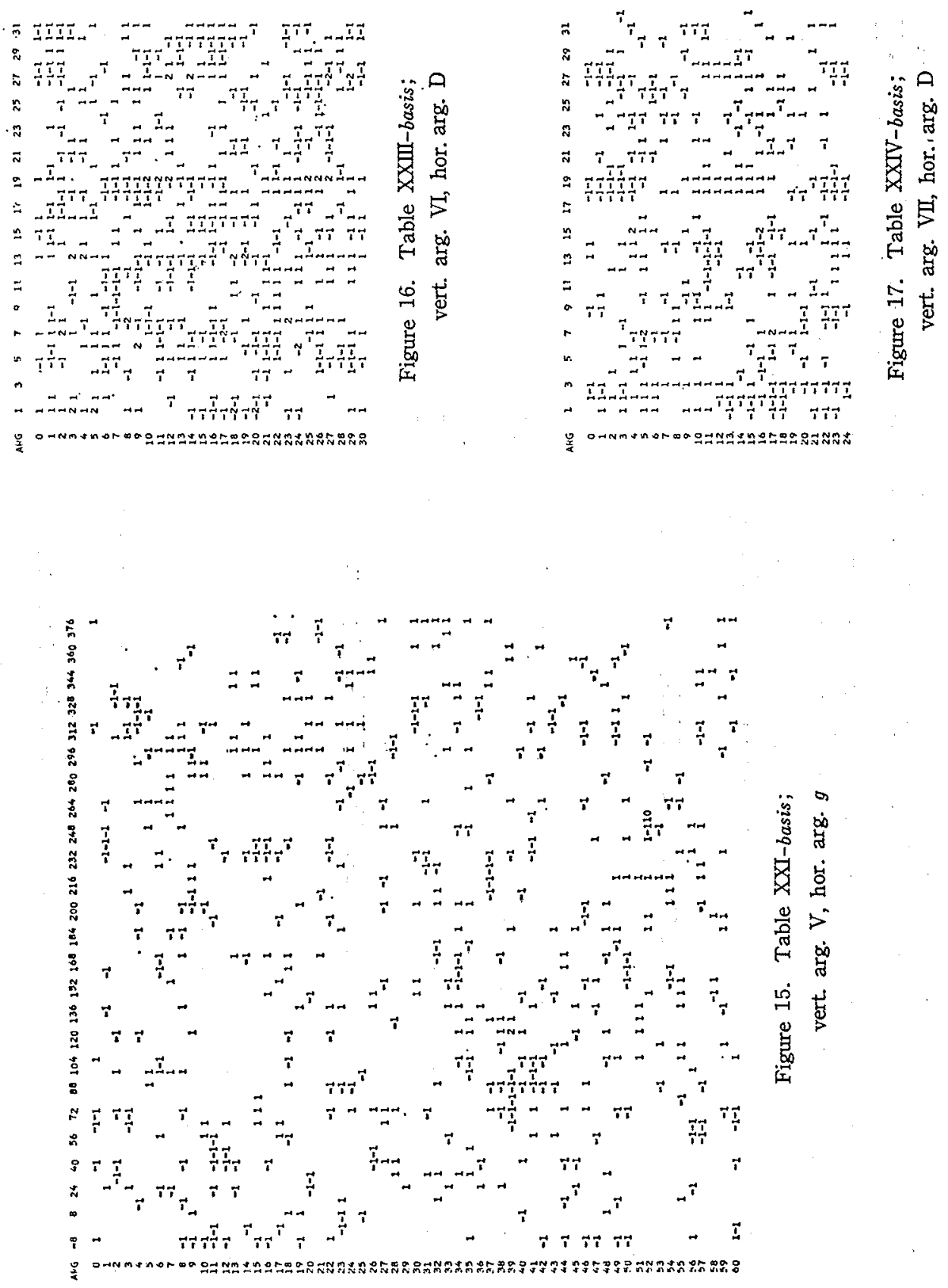

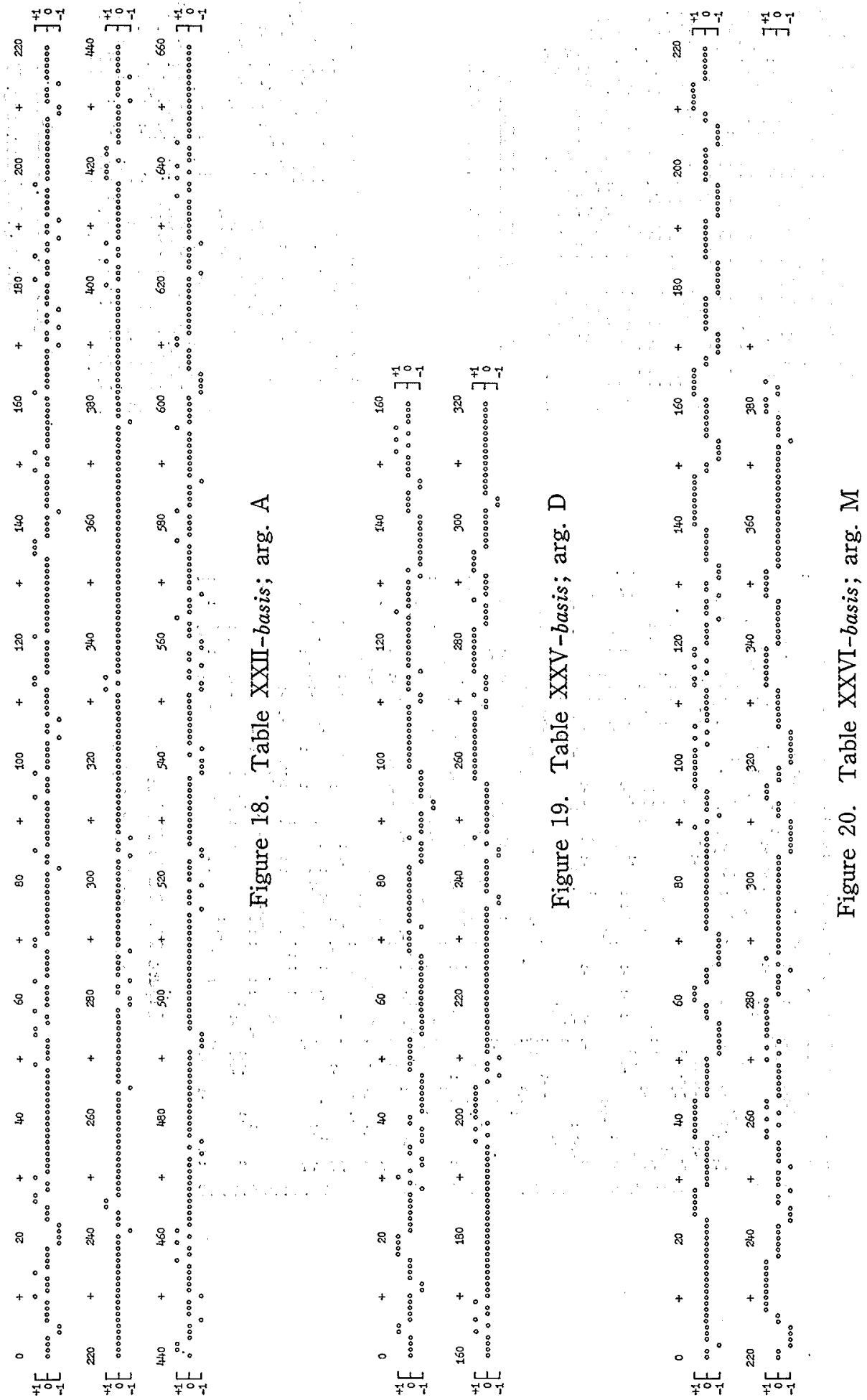


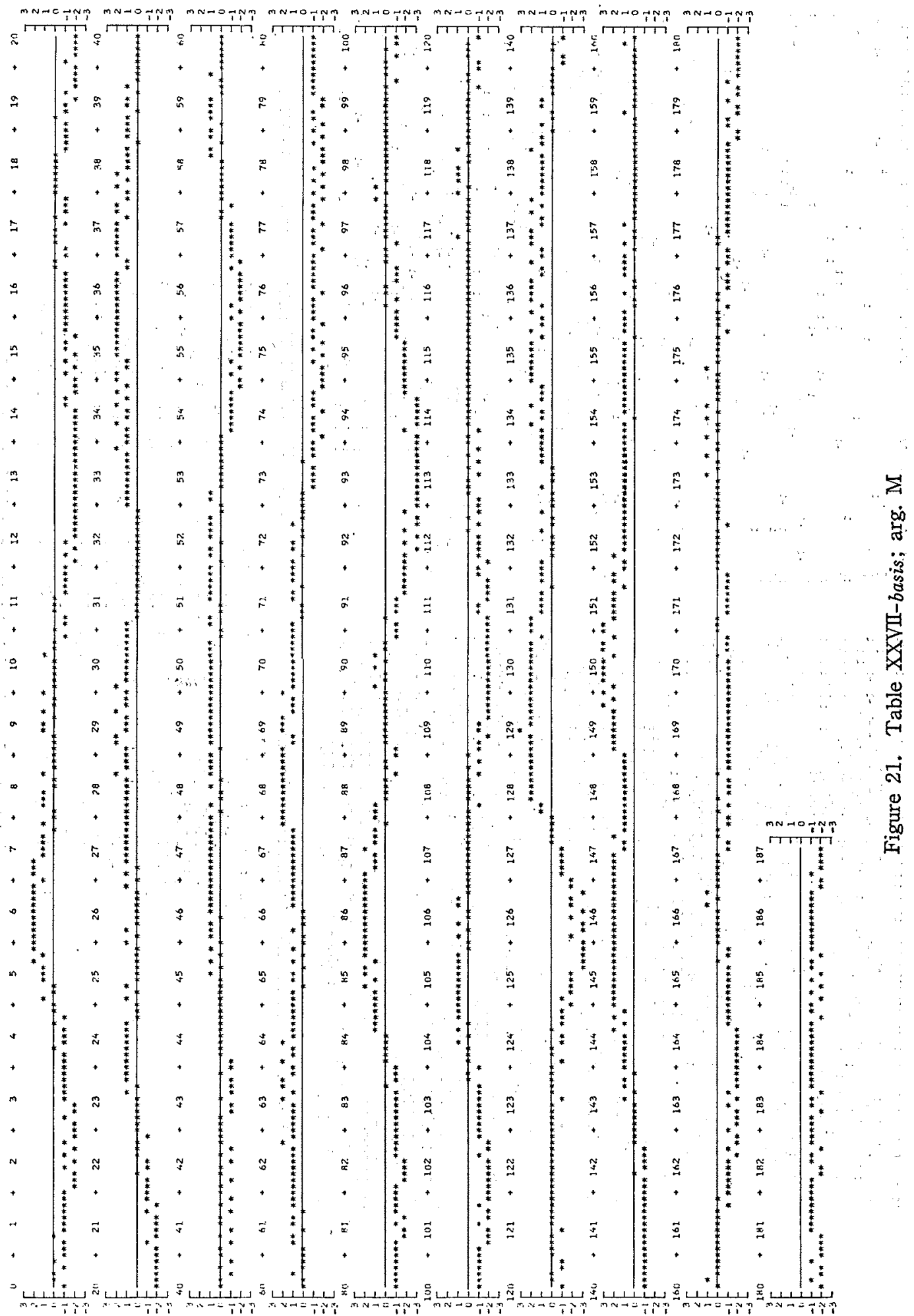




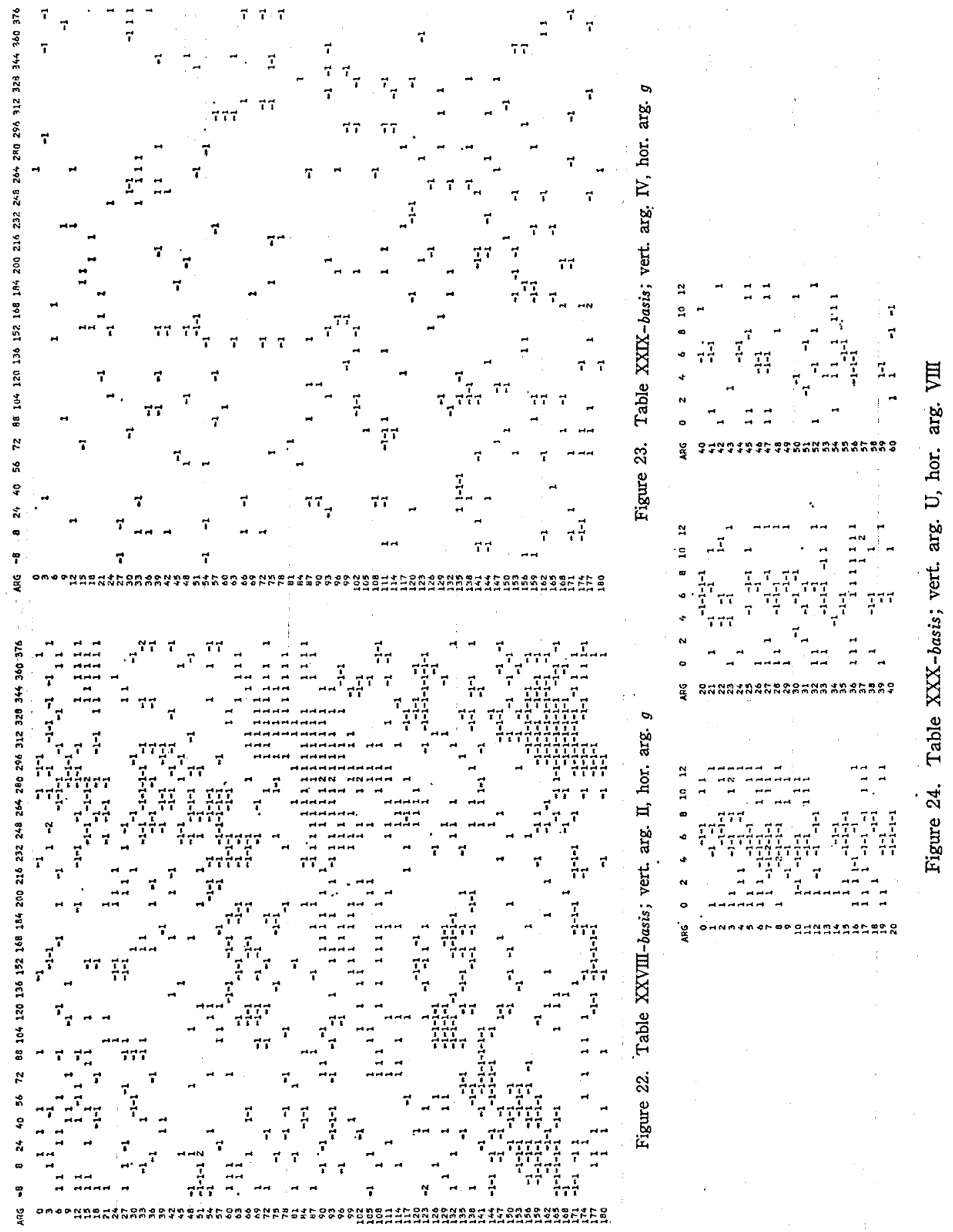


used for th construction of the tabulation (see basis, p. 21). The value of $j$ and the distinction between sine and cosine can be estimated by the appearance of the discrepancy. For example, $j=3$ and $\sin$ for $g=280$ in Figure 2 (or $2^{\prime}$ ), and $j=10$ and cos for $g=8$ in Figure 13 (or $13^{\prime}$ ).

The tabulations in the Tables do not include (a) the perturbations in the radius vector by Mercury (Table A), (b) the perturbations in the latitude by Mars and Saturn (Table F), (c) the several minor terms marked with asterisk concerning the perturbations by Moon (p. 18), and presumably (d) the smallest four terms by Venus (Table B) and two terms by Mars (Table $C$ ) in the perturbations of the radius vector referred to above. In fact, Newcomb might not expect such a high accuracy in his Tables as to adopt these small terms as well as the far smaller terms which appeared in his theory (Newcomb, 1891). He anticipated the error by about \pm 0.03 in the longitude at the end of the twentieth century due to the approximation adopted in the expressions of the mean anomalies of the disturbing planets (basis, p. 20). Williams and Clemence (1942) estimated the amount of the error in the perturbation in the radius vector to be about $2 \times 10^{-7}$ A.U. due to the omission of the terms depending solely on the mean anomaly of the earth. In the same paper they further remarked an error by -0 ". 17 in Newcomb's value of the perihelion longitude due to its motion in the interval between the epochs adopted by LeVerrier and Newcomb. Since this error directly reflects in the mean anomaly of the earth, do appear errors by $\pm 0^{\prime \prime} 006$ in the equation of center and $\pm 1.4 \times 10^{-8}$ A.U. in the radius vector, which are insignificant though.

\subsection{Programs of the TAO and the JHD}

In principle the programs of the TAO and of the JHD have been both prepared rigorously following the basis of the Tables with some modifications. The main properties are as follows. (Unless otherwise stated the symbols are those adopted in the $T a$ bles.)

(i) Arguments

a. Mean anomalies

Sun: To the expression of $g$ presented in the basis (p.9) the following correction is applied:

$$
\begin{aligned}
\Delta g= & \left(1^{\prime \prime} 882-0.016 T\right) \sin \left(57^{\circ} .24+150^{\circ} .27 T\right) \\
& +6 " .40 \sin \left(231^{\circ} .19+20^{\circ} .20 T\right)+0^{\prime \prime} 266 \sin \left(31^{\circ} .8+119^{\circ} .0 T\right)
\end{aligned}
$$

which is taken from the expression for $\delta L$ in the basis (p. 24).

Planets: "general values of $g_{1}$ " in Table G are adopted.

$$
\begin{array}{lll}
\text { Mercury } & g^{\prime}=102.199+149472^{\circ} .35 T \\
\text { Venus } & g^{\prime}=212.445+58517.493 T \\
\text { Mars } & g^{\prime}=319.582+19139.977 T \\
\text { Jupiter } & g^{\prime}=225.281+3034.583 T \\
\text { Saturn } & g^{\prime}=175.596+1221.794 T
\end{array}
$$

To the above value of $g^{\prime}$ for Jupiter the correction for the term of long period in its mean longitude due to Saturn's action is added. In the TAO-programs this correction is taken from Table $\mathrm{V}$ of the Tables by the linear interpolation. In the JHD-programs this 
correction is derived from Hill's (1895) Tables of Jupiter through the following procedure. The relevant term among the list of $\delta z$ in Hill's Tables (pp. 24, 25) is

$$
\text { [3.998 745-0. } \left.3^{d} 002213 m\right] \sin \left(5 g^{\prime}-2 g-81^{\prime \prime} .97009 t+67^{\circ} 08^{\prime} 55^{\prime \prime} 73\right) \text {, }
$$

and the quantity obtained through the multiplication of this terms by $n$ may correspond to the correction we concern. Numerical expressions of $g$ and $g^{\prime}$ and the value of $n$ are given on p. 23 of Hill's Tables and the value of $m$ is derived from the period of Jupiter's motion also shown on p.23. Consequently we have

$$
\Delta g=\left(0^{\circ} .3315-0.00155 T\right) \sin \left(133^{\circ} .9099+38^{\circ} .39365 T\right) \text {. }
$$

The value of the correction thus calculated are very close to those listed in Table $\mathrm{V}$ of the Tables. Maximum discrepacy between them is $\pm 0^{\circ} .02$ and is certainly insignificant in the calculation of the perturbations.

b. Quantities concerning the Moon's motion

The lunar inequality are expressed with the variables $D, g, g_{1}, u$ and $u^{\prime}$ (basis, p. 18). We may put

$$
u=L_{1}-\Omega \text { and } u^{\prime}=L^{\prime}-\Omega,
$$

where $L_{1}$ and $\Omega$ denote the mean longitude and the longitude of the mean ascending node of the Moon, respectively. The expressions for $D, g_{1}, L_{1}$ and $\Omega$ are taken from the Section 1 of Brown's Tables $(1919$, p. 28) in which the symbols $l$ and $L$ are used for $g_{1}$ and $L_{1}$, respectively. The expressions for $L$ and $g$ pertaining to the Sun are those given in the basis (p. 9).

\section{(ii) Elliptical terms}

The equation of the center and the radius vector in the elliptic orbit are directly calculated through the Kepler's equation using the values of the eccentricity and the mean anomaly of the date derived from the expressions in the basis (p. 9) with the correction $\Delta g$ by (5) to the latter.

(iii) Perturbations

All terms, including those omitted in the tabulations, listed in Tables $A$ to $F$ for the planets and those given on p. 18 for the Moon are adopted, except that the perturbations in the longitude by Venus are modified by "Tables VIII and XII" of Clemence's (1943) paper. The periodic perturbations by the planets are calculated through the $S K$ scheme in the TAO-programs and through the VCS-scheme in the JHD-programs.

Programs have been thus constructed at the TAO and the JHD independently and their computation results have been compared with each other. Discrepancies between them are around \pm 0 ".005 in the longitude, $\pm 0^{\prime \prime} .004$ in the latitude and $\pm 2 \times 10^{-8}$ A.U. in the radius vector. It is found that these discrepancies are mostly caused by the difference between the schema of $S K$ and VCS in the calculation of the perturbations by the planets. The discrepancies $S K-V C S$ for 1970 to 1979 are illustrated as an example in Figure 25. When this effect is removed, the discrepancies between the TAOand JHD-data are reduced to \pm 0 "001 both in the longitude and latitude and $1 \times 10^{-8}$ A.U. in the radius vector, namely to the one-tenth of the units of the respective last figures printed in the A.E. We may thus consider that the TAO- and the JHD-programs are both strictly consistent with Newcomb's theory and hence we can compare the TAO/JHD. 


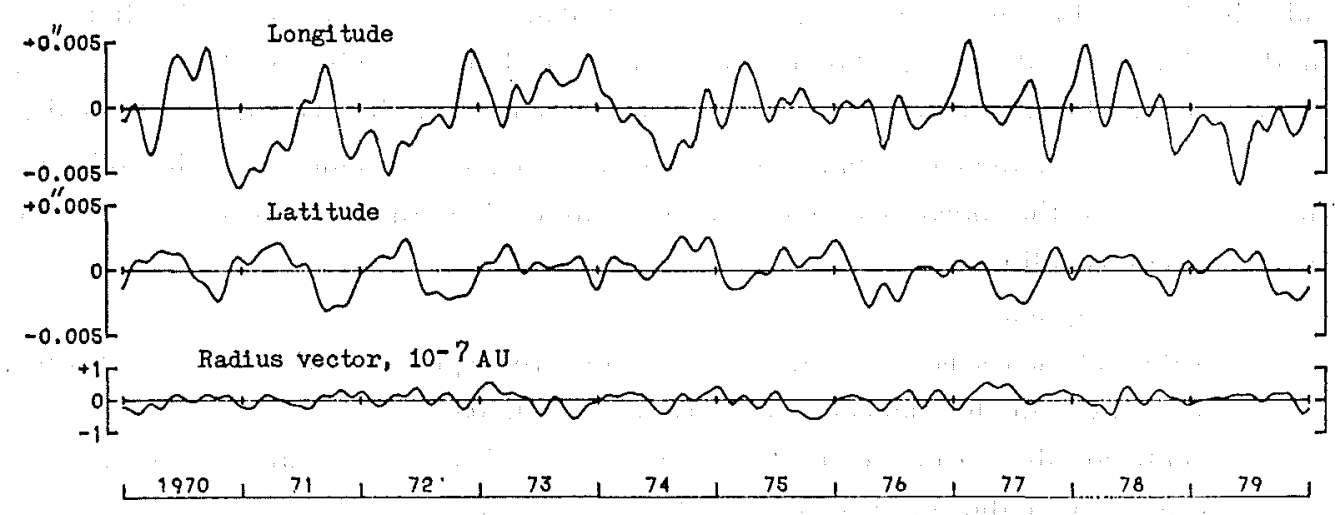

Figure 25. SK-VGS in the ecliptic coordinates of the Sun for 1970-1979.
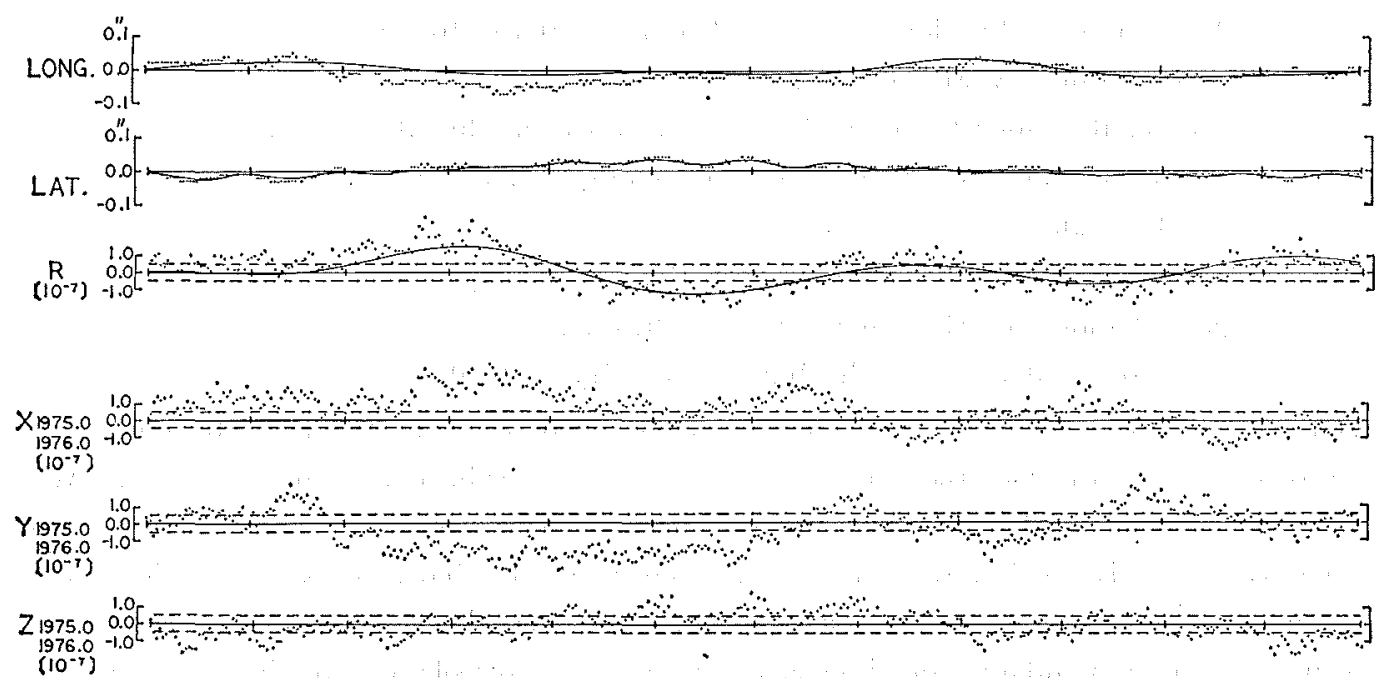

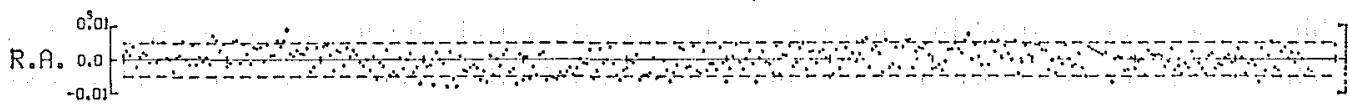
DEC. 0.001000 JAN FEB, MAR APR, MAY, JUN, JUL, AUG, SEP, OCT, NOV, DEC,

Figure 26. $A E-J H D$ in the ephemerides of the Sun for 1975. Each pair of horizontal broken-lines indicates the limit of agreemnt between the $\mathrm{AE}$ and JHD at the last decimal printed in the AE.

data with those published in the A.E.

\subsection{Comparison with the A.E.-data}

Discrepancies in the ephemerides of the Sun between the A.E.- and the JHD-data for the year of 1975 are presented in Figure 26. The pair of horizontal broken-lines in each figure indicates the one-half of the last unit printed in the A.E. Since the JHDdata are expressed down to the lower places than the A.E.-data, the individual dots in- 
side the broken-line pair denote that those A.E.-data exactly agree with the JHD-data at the printed last decimals. For the longitude and latitude only the dots locating on the respective abscissae correspond to the exact agreement at the printed last decimals.

Apart from the effect due to the random errors, we can enumerate the following inconsistencies of the tabulations with the basis to explain the discrepancies AE-JHD in the ecliptic coordinates.

\section{(i) Longitude}

values of the coefficients of the expression for the equation of the center, $( \pm 0$ " 010$)$.

$S K-V C S$ in the planetary perturbations ( \pm 0 " 003 ),

confusion due to unknown reason in the perturbations by Mars $( \pm 0$ " 03$)$,

confusion in the perturbations by Jupiter $( \pm 0,04)$,

the asterisked terms in the lunar inequality $( \pm 0$ " 013$)$.

(ii) Radius Vector

$S K-V C S$ in the planetary perturbations $\left( \pm 0.15 \times 10^{-7}\right.$ A.U.),

perturbations by Mercury $\left( \pm 1.1 \times 10^{-7}\right)$,

the smallest four terms by Venus and two terms by Mars $\left( \pm 0.4 \times 10^{-7}\right)$,

the asterisked terms in the lunar inequality $\left( \pm 0.8 \times 10^{-7}\right)$.

(iii) Latitude

$S K-V C S$ in the planetary perturbations $( \pm 0$ ".002),

perturbations by Mars and Saturn ( \pm 0 " 020$)$,

the asterisked terms in the lunar inequality ( \pm 0 " 014 ).

The resulting effects due to these causes, excepting for that due to the confusion in the perturbations in the longitude by Mars, are shown by solid curves in Figure 26. We can find that the residual discrepancies by removing these effects from the A.E.-data be-: come considerably smaller than the raw discrepancies AE-JHD. In particular the agreement in the latitude seems satisfactory. Kinoshita et al. (1974) estimated the mean values of the accumulated rounding error due to the interpolations in the respective tables to be about \pm 0 " 02 . in the case of the computation of the longitude by the Tables. This estimation may also be applicable to the error in the computation of the radius vector. Hence, on seeing the appearance of random discrepancies in Figures 1 to 24, we may regard the amounts of the residual discrepancies appeared in Figure 26 as reasonable provided that the A.E.-data have been calculated by making use of the individual tabulations in the Tables. However, the residual discrepancies both in the longitude and the radius vector still take positive or negative values continuously for some durations. They

Table 3 Comparison of calculations of the lunar inequality for 1975

\begin{tabular}{llc}
\hline & \multicolumn{1}{c}{ expansion fromula } & expansion - direct calculation \\
\hline Longitude & Newcomb, all terms & $+0.043 \sim-0,036$ \\
& Newcomb, without as terisked terms & $+.043 \sim-.025$ \\
& Kubo & $+.005 \sim-.006$ \\
\hline Latitude & Newcomb, all terms & $+0.007 \sim-00^{\prime \prime} 014$ \\
& Newcomb, without as terisked terms & $+.015 \sim-.014$ \\
& Kubo & $+.004 \sim-.004$ \\
\hline Radius vector & Newcomb, all terms & $+16 \sim-22 \times 10^{-8}$ \\
& Newcomb, without asterisked terms & $+14 \sim-21$ \\
& Kubo & $+3 \sim-3$
\end{tabular}


may not be attributed solely to the accumulation of random errors but may be presumably affected by: some slight discrepancies in the values of the arguments, in particular those depending on the mean anomalies, between the A.E.- and the JHD-computations.

In the basis (p.13) Newcomb advises to calculate the lunar inequalities directly by making use of the daily ephemerides of the Sun and the Moon instead of the formulas in the Tables, although the international and national ephemerides have never adopted this direct method. In Figure 27 the discrepancies of the calculations by the
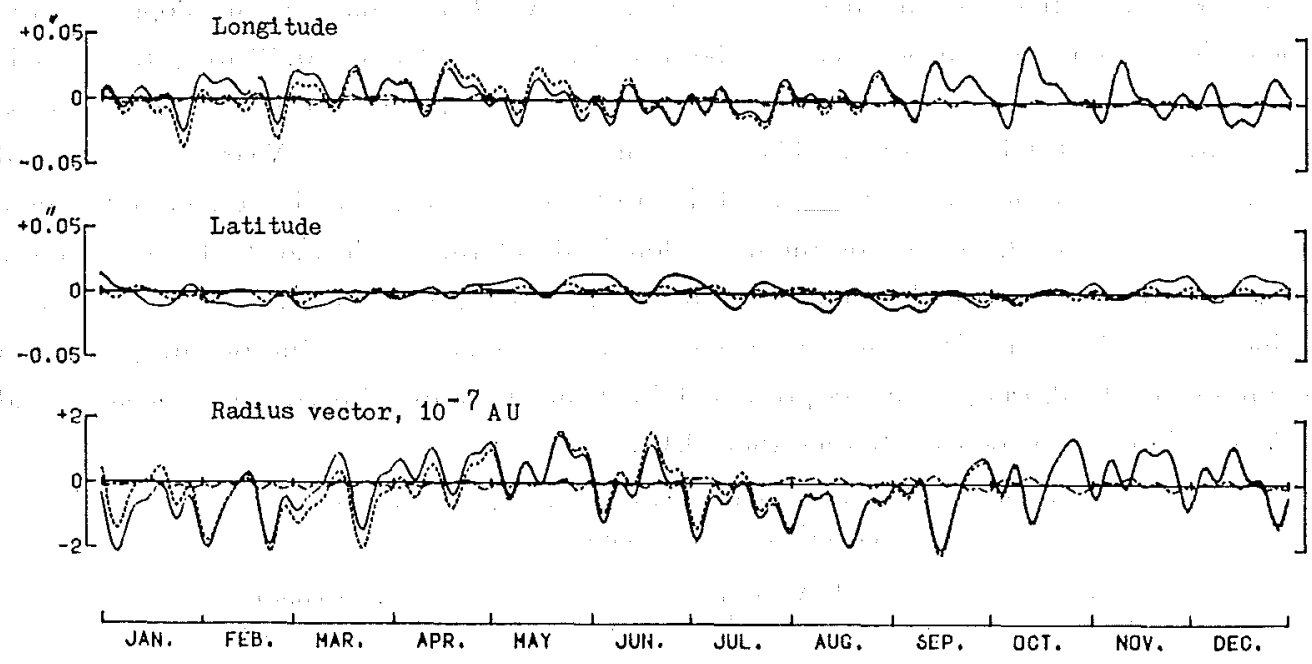

Figure 27. Discrepancies in the calculation of the perturbations produced by the Moon for 1975. Solid line = Newcomb's formula - direct calculation, broken line $=$ Newcomb's formula without asterisked terms - direct calculation, chain line = Kubo's formula - direct calculation.

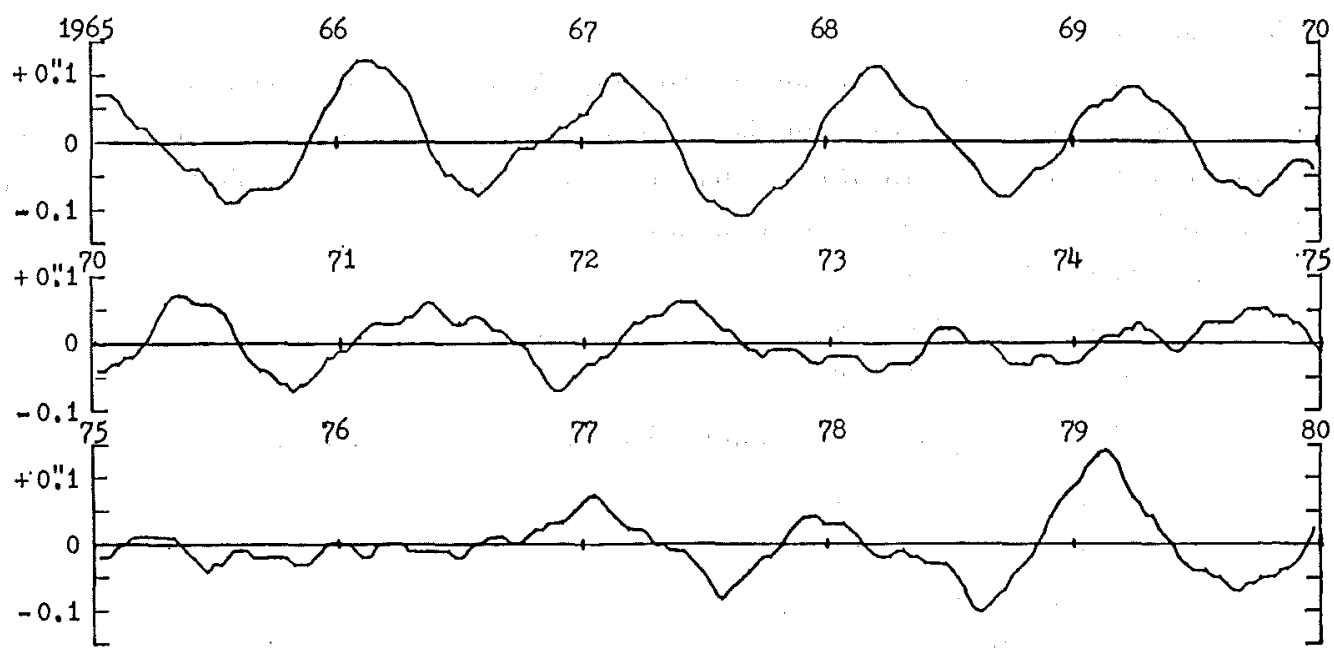

Figure 28. Discrepancy in the perturbations of the latitude of the Sun between LeVerrier's and Newcomb's Tables for 1965-1979. 
Tables from the direct calculations are illustrated together with those of the calculations through the formulas proposed by Kubo (unpublished). Their maximum discrepancies are summarized in Table 3.

As described in the basis (p. 13), Newcomb derived the planetary perturbations in the latitude (Table F) from the fundamental numbers given by LeVerrier (1958, pp. 13-20), on which LeVerrier's Tables are also based. Comparison of the actual amounts of the perturbations for 1965-79 between Newcomb's and LeVerrier's formulas is made in Figure 28. All the terms listed in the respective Tables have been adopted in the calculations. The discrepancy between both Tables ranges from -0.12 to +0 " 13 and is composed of discrepancies by \pm 0 " 06 in the perturbation by Venus, \pm 0 " 02 by Mars, \pm 0 " 03 by Jupiter and $\pm 0 \% 06$ by Saturn. The expressions $M \sin \left(j L^{\prime}+i L\right)+N \cos \left(j L^{\prime}+i L\right)$ and $\beta_{c} \cos \left(j g^{\prime}+i g\right)+\beta_{s} \sin \left(j g^{\prime}+i g\right)$ are used in LeVerrier's Tables and Newcomb's Tables, respectively, where $L$ stands for the mean longitude of the earth and $L^{\prime}$ for that of the disturbing planet. Through comparison of Newcomb's values of $\beta_{c}$ and $\beta_{s}$ with those deduced from LeVerrier's values of $M$ and $N$ using LeVerrier's value of the perihelion longitude for 1850, disagreements presented in Table 4 are found between Newcomb's and LeVerrier's terms which are larger than 0 " 01 .

Table 4 Disagreement in perturbations of latitude between LeVerrier's and Newcomb's Tables

\begin{tabular}{|c|c|c|c|c|c|c|c|c|}
\hline \multirow{2}{*}{$\underset{\text { by }}{\text { perturbations }}$} & \multicolumn{4}{|c|}{ LeVerrier } & \multicolumn{4}{|c|}{ Newcomb } \\
\hline & $j$ & $i$ & $M$ & $N$ & $j$ & $i$ & $\beta_{c}$ & $\beta_{s}$ \\
\hline Venus & $\begin{array}{r}+1 \\
0\end{array}$ & $\begin{array}{r}0 \\
+1\end{array}$ & $\begin{array}{r}60 \\
-4 \\
+6\end{array}$ & $\begin{array}{l}\text { 1) } \\
+16 \\
-23\end{array}$ & -1 & 0 & $\begin{array}{r}(0 . \\
-24\end{array}$ & $\begin{array}{l}\text { 01) } \\
+17\end{array}$ \\
\hline Mars & +1 & -1 & -1 & -10 & +2 & -2 & 0 & $\cdots+8$ \\
\hline Jupiter & 0 & +1 & -2 & -13 & & & & \\
\hline Saturn & +2 & -1 & -13 & -31 & & & & \\
\hline
\end{tabular}

\section{Inner planets}

Programs for the ephemerides of Mercury, Venus and Mars have been prepared in the same manner as for the Sun, being based on the respective bases in Newcomb's (1895c, d, 1898) Tables with Ross' (1917) correction to the mean orbital elements of Mars. Main features of the computations are as follows:

(i) General schema

$$
\begin{aligned}
& l=l_{0}+l_{1} T+l_{2} T^{2}+\delta l \\
& g=g_{0}+g_{1} T+g_{2} T^{2}+\delta l \\
& R=-\tan ^{2}\left(\frac{i}{2}\right) \sin 2 u+\frac{1}{2} \tan ^{4}\left(\frac{i}{2}\right) \sin 4 u-\frac{1}{3} \tan ^{6}\left(\frac{i}{2}\right) \sin 6 u \\
& u=l+\delta \lambda_{p}+(v-g)-\theta \\
& \lambda=u+\theta+R \\
& \beta=\sin ^{-1}(\sin i \sin u)+\delta \beta_{p} \\
& r=r_{e l l} \times 10^{\delta(\log r p)}
\end{aligned}
$$

The respective first three terms of (7) and (8) are those for the mean longitude and the mean anomaly presented at the beginning of each basis (pp. 173, 273) for Mercury and Venus. For Mars they are taken from the elements derived by Ross (1917, p. 263). The 
correction $\delta l$ is taken from $(\beta),(\gamma)$ and $(\delta)$ on p. 280 for Venus and from $(\beta)$ and $(\gamma)$ p. 399 for Mars :

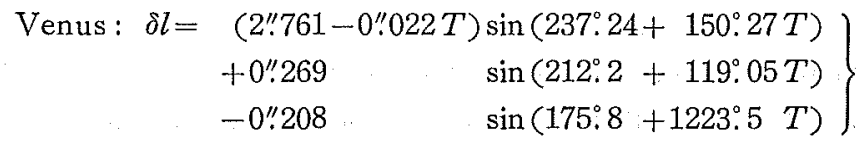

$$
\begin{aligned}
& \text { Mars : } \quad \delta l=0.606 \sin \left(212^{\circ} .87+119^{\circ} 051 T\right) \\
& +0.009 \sin \left(325^{\circ} .00+753^{\circ} .67 T\right) \\
& +0.130 \sin \left(74.00+163^{\circ} .00 \mathrm{~T}\right) \\
& +0.280 \sin \left(300^{\circ} 00+40^{\circ} 80 \mathrm{~T}\right) \\
& +0^{\prime \prime} 319 \sin \left(116^{\circ} .88+773^{\circ} .444 T\right) \\
& +52^{\prime \prime} 490 \sin \left(47^{\circ} .48+19^{\circ} .771 T\right) \\
& -37 " 05-13 " 50 T \text {. }
\end{aligned}
$$

No corrections are applied to the mean longitude and mean anomaly for Mercury. The equation of the center $v-g$ and the radius vector $r_{e l l}$ of the elliptic orbit are calculated directly by solving the Kepler's equation with the values of $g$ by (8) and $e$ of the date. In the case of Mars, the following corrections are applied:

$$
\begin{aligned}
\delta(v-g) & =0 / 043 \sin 2 g \\
10^{9} \delta(\log r) & =-465 \cos g-105 \cos 2 g
\end{aligned}
$$

The former correction is given as $\delta E$ on p. 389, but the latter is different from the expression of $\delta(\log r)$ on p. 389 due to the numerical inconsistency among the expressions of $e$ on p. 388, $\delta(\log r)$ and $\log r$ on p. 389. The tabular values of the logarithm of the radius vector in Table XXXIII were presumably calculated by the expression of $\log r$ on p. 389. Whence (17) is deduced by subtracting the series expansion of the logarithm of the radius vector with the value of $e$ on p. 388 from the expression of $\log r$ on p. 389 . The values of the equation of the center and the radius vector thus corrected by (16) and (17) should be respectively treated as the terms $v-g$ in (10) and $r_{e l l}$ in (13), although these corrections are not associated with the elliptic orbit but originally arise from the perturabtions.

(ii) Perturbations $\left(\delta \lambda_{p}, \delta \beta_{p}, \delta\left(\log r_{p}\right)\right.$ in (10), (12), (13))

a. As a rule all terms listed in the tables with titles in the alphabetical order are adopted. But if there is any expression in the description of the basis regarding the same term as contained in the alphabetical tables, the expression in the description is adopted with priority.

b. The argument $g$ of each perturbed planet includes the correction $\delta l$ stated above.

c. Mercury: No modifications are applied to Tables A, B, C and D.

d. Venus: Table $B$ is amended according to the footnote on p. 276 . Table $E$ is amended according to the description in $(\delta)$ on p. 280 and another description on p. 277 as follows,

$$
\begin{array}{ll}
-0^{\prime \prime} .208 \sin \left(175^{\circ} 8+1223^{\circ} 5 T\right) \text { instead of } & +0^{\prime \prime} .208 \cos \left(270^{\circ}-g^{\prime}\right), \\
+0^{\prime \prime} 180 \sin \left(l^{\prime}-l\right) & +0^{\prime \prime} .180 \cos \left(129^{\circ} .4-g^{\prime}+g\right), \\
-0^{\prime \prime} .051 \sin 2\left(l^{\prime}-l\right) & +0^{\prime \prime} .051 \cos \left(348^{\circ} .7-2 g^{\prime}+2 g\right) .
\end{array}
$$

e. Mars: Mean anomalies of Jupiter and Saturn are amended according to the 
description on p. 398 ,

$$
\begin{aligned}
& \Delta g^{\mathrm{V}}=+0^{\circ} .332 \sin \left(134^{\circ} .4+38^{\circ} .5 T\right), \\
& \Delta_{g} \mathrm{~V}=-0.808 \sin \left(134^{\circ} .4+38^{\circ} .5 T\right) .
\end{aligned}
$$

The former expression should be substantially identical with (6).

As in the case of the Sun the TAO-programs adopt the $S K$-scheme and the JHD-programs adopt the $V C S$-scheme to calculate the periodic perturbations. When the effect due to this difference is taken into account, the heliocentric ephemerides of the inner planets computed by the TAO and the JHD agree well with each other within \pm 0 ".001 in the longitudes and latitudes and $\pm 1 \times 10^{-8}$ A.U. in the radius vectors, i.e. one-hundredth and one-tenth of the respective last decimals in the A.E.

Results of comparison of the A.E.-data with the JHD-data are exhibited in Figures 29 and 30. Each pair of the horizontal broken-lines indicates the limit of the agreement of the both data at the printed last decimal of the A.E. The agreement in the heliocentric ephemerides between the A.E.- and the JHD-data seems permissible on the whole, except that the radius vector of Mercury in the A.E. are systematically smaller than the JHD-values.

Although the discerapncies $\mathrm{AE}-\mathrm{JHD}$ in the ephemerides of the Sun can be re-
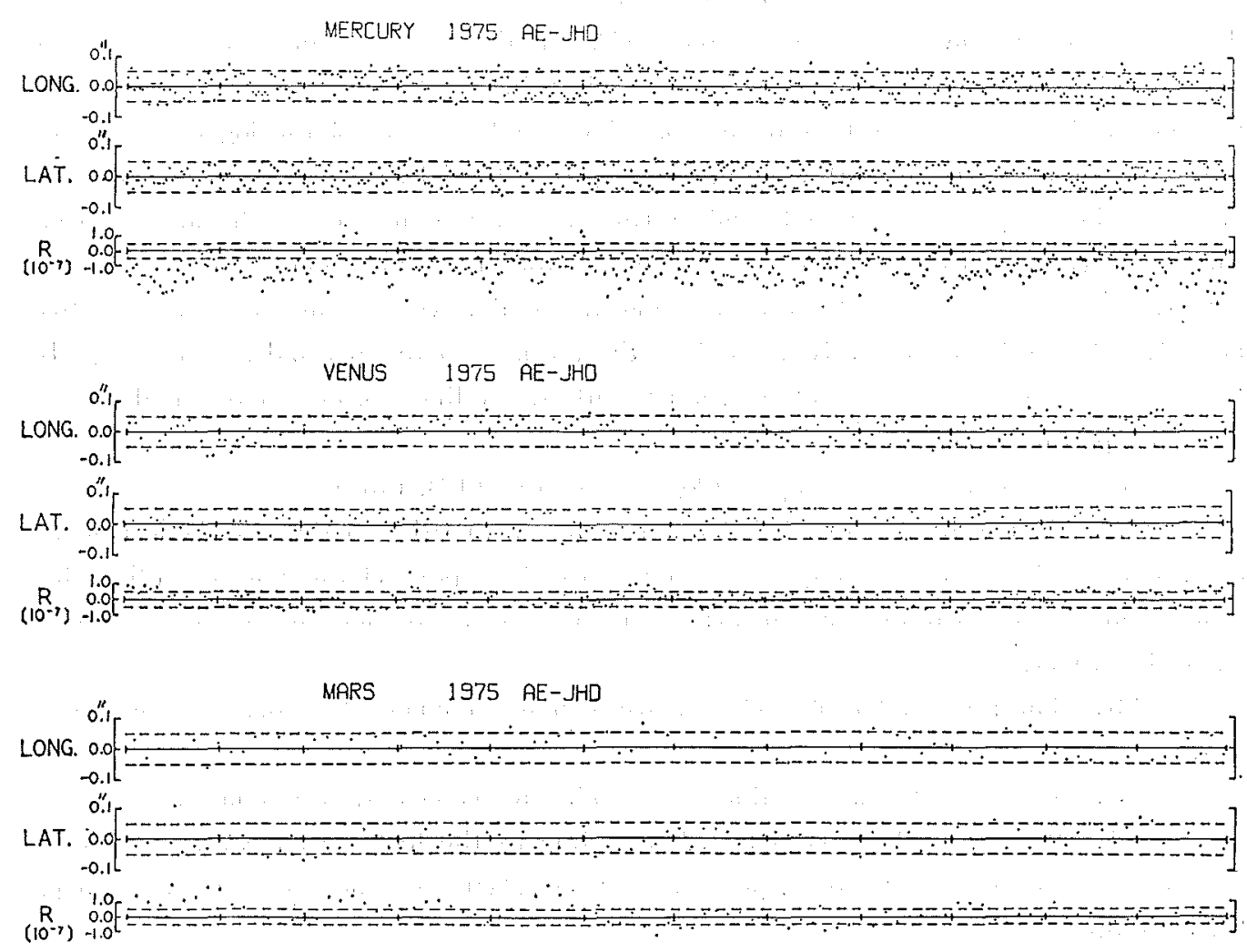

JPN, FEB, MAR , APP, MAY, JUN, JUL, AUG, SEP, OCT, NOV, DEC,

Figure 29. AE-JHD in the heliocentric ephemexides of the inner planets for 1975. 
R.P. ${ }_{0.0}^{0.02}\left[\begin{array}{lll}\text { MERCURY } 1975 \text { AE-JHD } \\ -0.01\end{array}\right.$

OEC. 0.040 .10

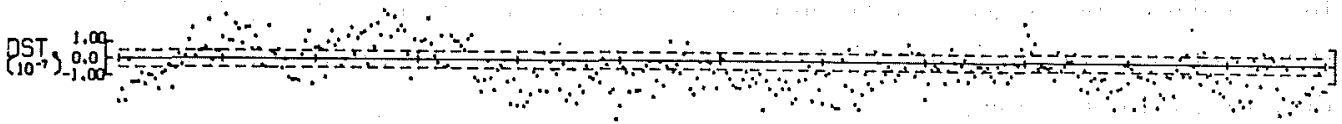

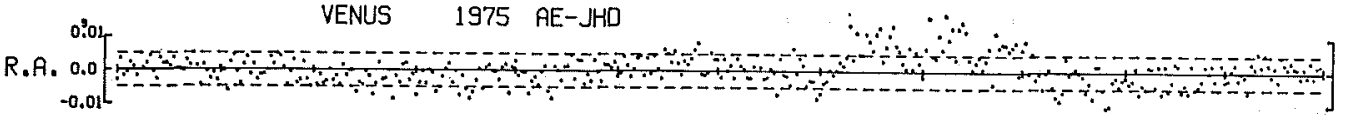
OEC. 0.040 .10

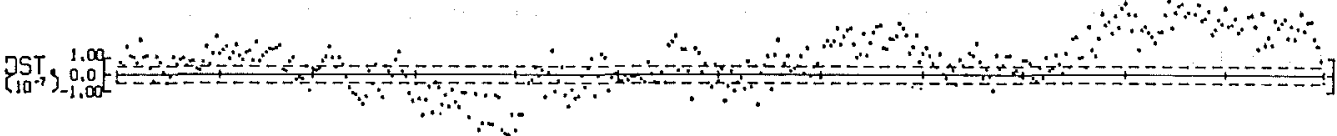

R.A. ${ }^{0.0}\left[\begin{array}{lll}\text { MARS } 1975 \text { AE-JHD } \\ \text {-0.01 }\end{array}\right.$ OEC. 0.04 . QST, $\log _{10}^{0,00}$, JAN FEB MAR , APR . MAY, JUN, JUL , AUG, SEP , OCT, NOV, DEC

Figure 30. AE-JHD in the geocentric ephemerides of the inner planets for 1975.
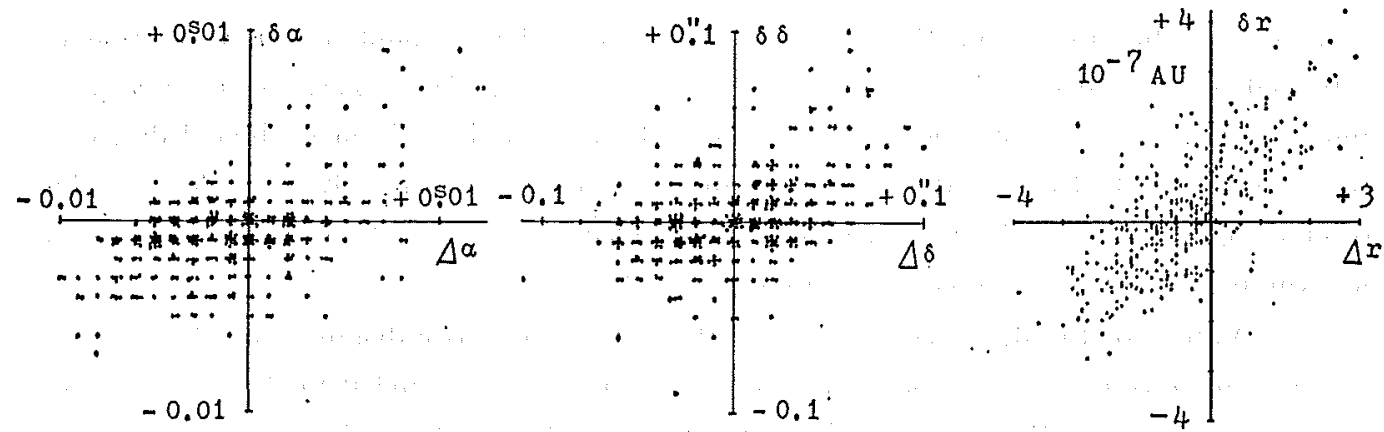

Figure 31. Effect of the discrepancies in the basic ephemerides to the geocentric ephemerides of Mercury for 1975. 
garded as inevitable from the standpoint of the computation and as insignificant for the use of the comparison with observation of the Sun itself, we should not underestimate these discrepancies, any of which may cause a significant discrepancy in the geocentric ephemerides of the planets. An example of the propagation of such an error is illustrated in Figure 31. The abscissa in each figure denotes the actual discrepancy AE-JHD in the geocentric coordinates of Mercury and the ordinate denotes the combined effect to the calculation of the geocentric coordinates due to the discrepancies AE-JHD in the Sun's coordinates and in the Mercury's heliocentric coordinates. In the case of the geocentric distance $r_{M}$ for example,

where

$$
\begin{aligned}
& \Delta r_{M}=r_{M}(\mathrm{AE})-r_{M}(\mathrm{JHD}), \\
& \delta r_{M}=a \delta \lambda_{S}+b \delta \beta_{S}+c \delta R_{S}+d \delta \lambda_{M}+e \delta \beta_{M L}+f \delta R_{M Y},
\end{aligned}
$$

$$
a=\frac{\partial r_{M I}}{\partial \lambda_{S}}, \quad \delta \lambda_{S}=\lambda_{S}(\mathrm{AE})-\lambda_{S}(\mathrm{JHD}), \quad \text { etc. }
$$

and the suffixes $M$ and $S$ designate Mercury and the Sun respectively. We can find existence of correlations of $\Delta \alpha_{M}$ against $\delta \alpha_{M L}, \Delta \delta_{M I}$ against $\delta \delta_{M I}$, and $\Delta r_{M L}$ against $\delta r_{M I}$, respectively.

\section{Outer planets}

Numerical integrations of the heliocentric rectangular coordinates of Jupiter, Saturn, Uranus, Neptune and Pluto have been performed at the JHD rigorously following the calculation scheme and the initial values presented in Eckert, Brouwer and Clemence's (1951) computations. Agreements of the results with Eckert et al.'s values are so satisfactory that only less than 0.5 per cent of the data have yielded the discrepancies by \pm 1 at the printed last decimal, $10^{-8}$ A.U. The heliocentric spherical coordinates in the A.E. do not contain Clemence's (1954) correction due to the perturbations by the inner planets, and the comparison with the JHD-data has not been made for these ephemerides. The discrepancies $\mathrm{AE}-\mathrm{JHD}$ in the geocentric ephemerides are rather significant as shown in Figure 32. Besides the effect due to the discrepancies in the Sun's ephemerides, the right ascensions and declinations in the A.E. include the error due to a simplified procedure of the correction for the change in the value of the aberration constant from Newcomb's value to that of the IAU (1964) System. The amount of this correction is $-0.0000073 \Delta \times$ (daily motion) as given in the Explanatory Supplement to the A.E. (3rd imp., p. 507). In the A.E.-calculation this correction might have been evaluated down to the same decimal places as those of the printed last figures in the A:E. and added to the original figures expressed also down to the same places. The effect due to this procedure is exhibited by discontinuous curves in Figure 32 .

Values of the discrepancies AE-JHD in the geocentric distances of Uranus and Neptune both concentrate strongly in the range between -1 and 0 in the unit of the printed last decimal, their mean values being $-5.5 \times 10^{-7}$ and $-5.4 \times 10^{-7}$ A.U., respectively. The A.E. tabulates presumably these quantities by omitting the figures lower than the printed last decimal.

Frequency distributions of the discrepancies AE-JHD are summarized in Table 5 


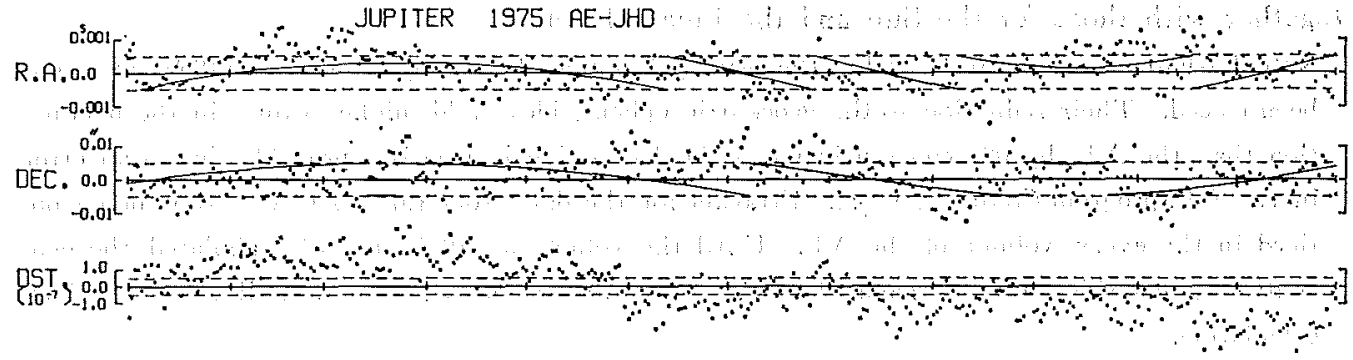

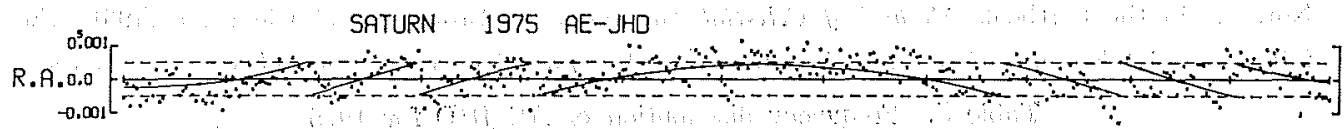

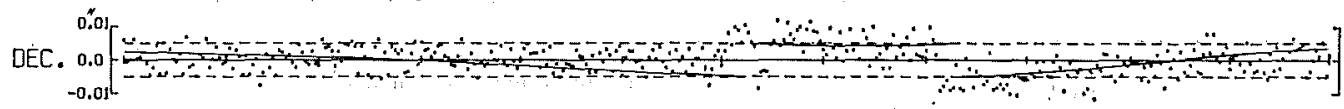

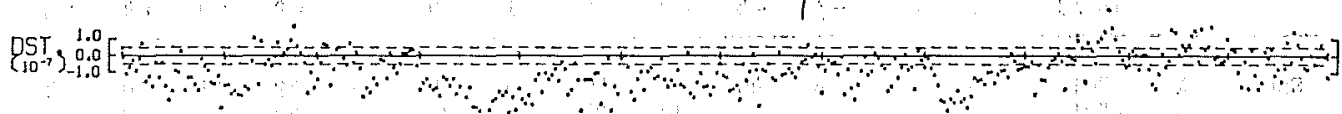
URANUS $1975 \mathrm{AE}-\mathrm{JHO}$

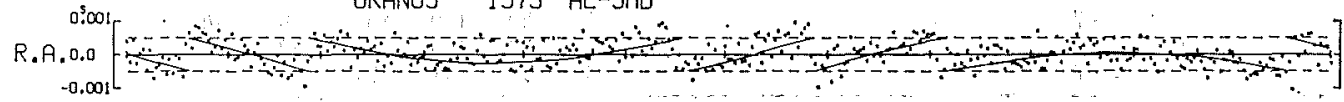

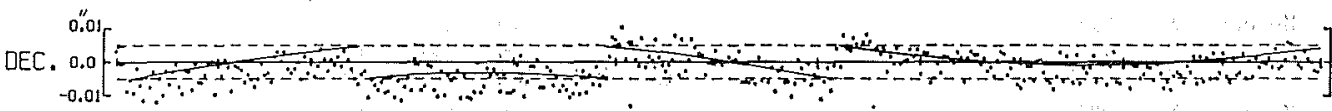

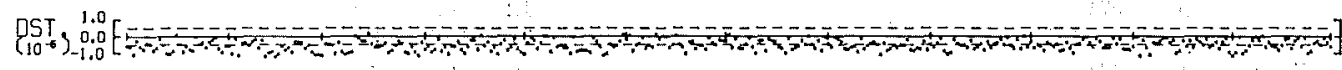

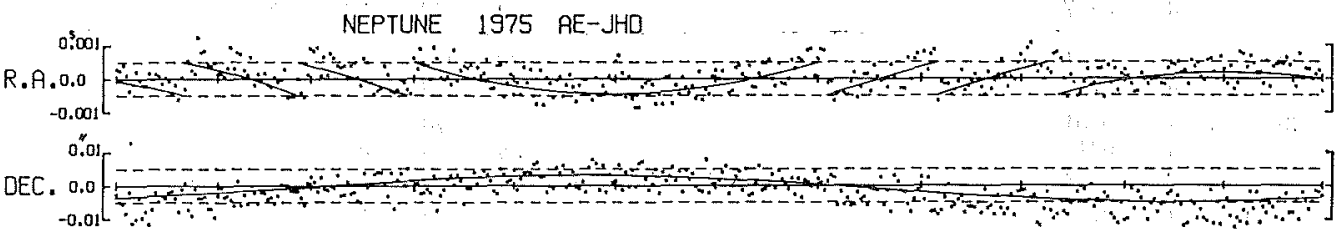

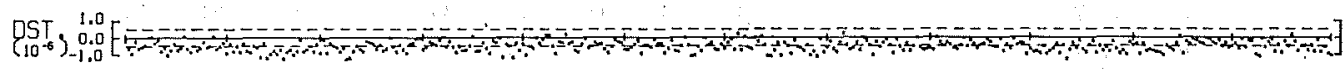

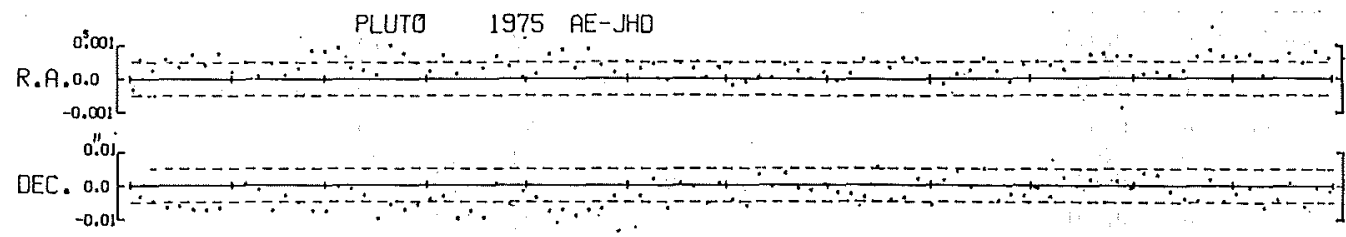

QST $\int_{10}^{1.00} 000$ JAN, FEB, MRR, APR, MAY, JUN, JUL, AUG, SEP, OCT, NOV, DEC

Figure 32. AE - JHD in the geocentric ephemerides. of the outer plantes for 1975. Discontinuous curves indicate the defect in the planetary aberration. 
together with those for the Sun and the inner planets.

Note 1.-Numerical integrations for the principal minor planets by Duncombe (1969) have not been traced. Their reduction to the geocentric ephemerides yields higher values in the declination than the A.E. by 0.1 constantly when the declination is negative, probably due to an error in the A.E.-program (Wilkins, 1974). Erratum for the data from 1972 to 1980 is thus being noticed in the every volume of the A.E. Until the volume for 1971 the A.E. tabulated the geocentric ephemerides deduced from Herget's (1962) integrations and agrees well with the JHDcalculation.

Note 2.-In the textbook Method of Celestial Mechanics by Brouwer and Clemence (1961) the following mistakes have been found concerning the numerical integration of Cowell's method.

Table 5. Frequency distribution of AE-JHD for 1975

\begin{tabular}{|c|c|c|c|c|c|c|c|c|c|c|c|c|c|c|c|}
\hline & \multirow{2}{*}{\multicolumn{2}{|c|}{$\begin{array}{l}\text { last } \\
\text { decimal } \\
\text { in } \mathrm{AE}\end{array}$}} & \multirow[b]{2}{*}{-7} & \multirow[b]{2}{*}{-6} & \multirow[b]{2}{*}{-5} & \multirow[b]{2}{*}{-4} & \multicolumn{6}{|c|}{ (Untt: last decinals in $A E$ ) } & \multirow[b]{2}{*}{+3} & \multirow[b]{2}{*}{+4} & \multirow[b]{2}{*}{+5} \\
\hline & & & & & & & -3 & -2 & -1 & 0 & +1 & +2 & & & \\
\hline \multirow[t]{2}{*}{ Sun } & $\begin{array}{l}\lambda \\
\beta \\
R\end{array}$ & $\begin{array}{l}0: 01 \\
0: 01 \\
E-7^{*}\end{array}$ & 5 & 5 & 14 & 40 & $\begin{array}{l}55 \\
18\end{array}$ & $\begin{array}{l}49 \\
34 \\
13\end{array}$ & $\begin{array}{l}56 \\
76 \\
89\end{array}$ & $\begin{array}{r}24 \\
73 \\
114\end{array}$ & $\begin{array}{r}40 \\
89 \\
119\end{array}$ & $\begin{array}{l}42 \\
39 \\
23\end{array}$ & $\begin{array}{r}21 \\
26 \\
7\end{array}$ & $\begin{array}{l}10 \\
10\end{array}$ & 4 \\
\hline & $\begin{array}{l}X^{* *} \\
Y \\
Z\end{array}$ & $\begin{array}{l}E-7 \\
E-? \\
E-7\end{array}$ & & & & & 7 & $\begin{array}{r}2 \\
75 \\
8\end{array}$ & $\begin{array}{l}49 \\
89 \\
89\end{array}$ & $\begin{array}{l}110 \\
108 \\
191\end{array}$ & $\begin{array}{r}131 \\
66 \\
70\end{array}$ & $\begin{array}{r}58 \\
18 \\
6 \\
\end{array}$ & $\begin{array}{r}14 \\
1\end{array}$ & & \\
\hline Mercury & $\begin{array}{l}\lambda \\
\beta \\
R\end{array}$ & $\begin{array}{l}0: 1 \\
0: 1 \\
E-7\end{array}$ & & & & 1 & 16 & 107 & $\begin{array}{r}19 \\
8 \\
161\end{array}$ & $\begin{array}{r}312 \\
348 \\
71\end{array}$ & $\begin{array}{l}35 \\
10 \\
10\end{array}$ & & & & \\
\hline Venus & $\begin{array}{l}\lambda \\
\beta \\
R\end{array}$ & $\begin{array}{l}0: 1 \\
0: 1 \\
E-7\end{array}$ & & & & & & & $\begin{array}{l}10 \\
12 \\
19\end{array}$ & $\begin{array}{l}156 \\
162 \\
139\end{array}$ & $\begin{array}{r}17 \\
9 \\
25\end{array}$ & & & & \\
\hline Mars & $\begin{array}{l}\lambda \\
\beta \\
R\end{array}$ & $\begin{array}{l}0: 1 \\
0 ! 1 \\
E-7\end{array}$ & & & & & & & $\begin{array}{l}2 \\
? \\
9\end{array}$ & $\begin{array}{l}79 \\
81 \\
52\end{array}$ & $\begin{array}{r}11 \\
4 \\
27\end{array}$ & 4 & & & \\
\hline Sun & $\alpha$ & $\begin{array}{l}0: 01 \\
0: 1\end{array}$ & & & & & & & $\begin{array}{l}32 \\
29\end{array}$ & $\begin{array}{l}315 \\
299\end{array}$ & $\begin{array}{l}18 \\
37\end{array}$ & & & & \\
\hline Mercury & $\begin{array}{l}a \\
\delta \\
r\end{array}$ & $\begin{array}{l}0.01 \\
0: 1 \\
\mathrm{E}-7\end{array}$ & & & & 1 & 22 & 62 & $\begin{array}{r}60 \\
25 \\
108\end{array}$ & $\begin{array}{r}278 \\
298 \\
96\end{array}$ & $\begin{array}{l}27 \\
41 \\
53\end{array}$ & $\begin{array}{r}1 \\
20\end{array}$ & 3 & & \\
\hline Venus & $\begin{array}{l}a \\
\delta \\
r\end{array}$ & $\begin{array}{l}0.01 \\
0: 1 \\
\mathrm{E}-7\end{array}$ & & & & 3 & 8 & 15 & $\begin{array}{l}32 \\
36 \\
42\end{array}$ & $\begin{array}{r}284 \\
275 \\
89\end{array}$ & $\begin{array}{l}47 \\
53 \\
93\end{array}$ & $\begin{array}{r}2 \\
1 \\
53\end{array}$ & 41 & 19 & 2 \\
\hline Mars & $\begin{array}{l}a \\
b \\
r\end{array}$ & $\begin{array}{l}0: 01 \\
0: 1 \\
\mathrm{E}-7\end{array}$ & & & & & 5 & 30 & $\begin{array}{l}29 \\
26 \\
64\end{array}$ & $\begin{array}{r}310 \\
314 \\
77\end{array}$ & $\begin{array}{l}26 \\
25 \\
85\end{array}$ & 63 & 31 & 10 & \\
\hline Juplter & $\begin{array}{l}a \\
\delta \\
r\end{array}$ & $\begin{array}{l}0.501 \\
0: 01 \\
E-?\end{array}$ & & & & 3 & 18 & 61 & $\begin{array}{l}47 \\
55 \\
87\end{array}$ & $\begin{array}{r}240 \\
230 \\
62\end{array}$ & $\begin{array}{l}78 \\
81 \\
79\end{array}$ & $\begin{array}{r}1 \\
46\end{array}$ & 11 & 1 & \\
\hline Saturn & $\begin{array}{l}a \\
\delta \\
r\end{array}$ & $\begin{array}{l}05001 \\
0: 01 \\
E-7\end{array}$ & & & & 3 & 30 & 87 & $\begin{array}{r}42 \\
44 \\
116\end{array}$ & $\begin{array}{r}255 \\
275 \\
96\end{array}$ & $\begin{array}{l}69 \\
47 \\
28\end{array}$ & 5 & 1 & & \\
\hline Uranus & $\begin{array}{l}a \\
\delta \\
r\end{array}$ & $\begin{array}{l}05001 \\
0.01 \\
E-6\end{array}$ & & & & & & & $\begin{array}{r}31 \\
110 \\
206\end{array}$ & $\begin{array}{l}287 \\
239 \\
160\end{array}$ & $\begin{array}{l}48 \\
17\end{array}$ & & & & \\
\hline Neptune & $\begin{array}{l}a \\
\delta \\
r\end{array}$ & $\begin{array}{l}0.001 \\
0.01 \\
E-6\end{array}$ & & & & & & & $\begin{array}{r}29 \\
104 \\
198\end{array}$ & $\begin{array}{l}277 \\
234 \\
167\end{array}$ & $\begin{array}{l}59 \\
17\end{array}$ & & & & \\
\hline Pluto & $\begin{array}{l}a \\
\delta \\
I\end{array}$ & $\begin{array}{l}0.001 \\
0: 01 \\
E-6\end{array}$ & & & & & & & $\begin{array}{r}131 \\
48\end{array}$ & $\begin{array}{l}222 \\
224 \\
316\end{array}$ & $\begin{array}{r}144 \\
11 \\
2\end{array}$ & & & & \\
\hline
\end{tabular}

* $\mathrm{E}-\mathrm{n}$ stands for $10^{-\mathrm{n}} \mathrm{A}, \mathrm{U}$.

* Values for the nearest beginning of year. Those for 1950.0 exhibit similar

frequency distributions. 
In the seventh line of p. 172, $w k=0.1720210182$ should be read as $w k=0.1720210039$. The former figure means $M w k$ and the latter $\sqrt{M} w k$. This mistake affects the numerical values in the succeeding calculation. In the lines of 13 to 15 of the same page, $w k \dot{x}, w k \dot{y}, w k \dot{z}$ should be read as $w \dot{x}, w \dot{y}, w \dot{z}$, respectively.

\section{Moon}

Programs of $j=1$ and $j=2$ ephemerides of the Moon were prepared at the JHD (Inoue, 1977) rigorously following the theories of the Improved Lunar Ephemeris (Eckert, Jones and Clark, 1954) and of Eckert, Walker and Eckert (1966), respectively. There were several minor discrepancies between the JHD-programs for $j=2$ ephemerides and those of Fundamental Lunar Ephemeris (FLE) prepared by Van Flandern (1976) at the U.S. Nautical Almanac Office, and by removing the some causes of the discrepancies the JHD-ephemerides have agreed with the FLE within \pm 0 ".002 in the longitude and latitude and $\pm 2^{\prime \prime} \times 10^{-6}$ in the horizontal parallax to be compared with their respective last units in the A.E., $0^{\prime \prime} 01$ in the longitude and latitude and $1^{\prime \prime} \times 10^{-4}$ in the horizontal parallax. We may thus consider that the programs for $j=2$ ephemerides of the JHD and USNAO are both sufficiently in accordance with Brown-Eckert theory. Discrepancies AE-JHD are summarized in Table 6. They may be mostly caused by the defects in the A.E.-programs, for example, the incomplete treatment of the corrections for $j=2$ ephemerides due to the change in the value of the dynamical form factor of the earth from Brown's value to that of the IAU (1964) System. It is estimated that the accuracies of $j=2$ ephemerides in

Table 6 Frequency distribution of $\mathrm{AE}-\mathrm{JHD}$ in the ephemerides of the Moon (Inoue, 1977)

\begin{tabular}{|c|c|c|c|c|c|c|c|}
\hline \multirow{2}{*}{$\begin{array}{c}\text { discrepancy } \\
\text { in } \\
\text { last unit }\end{array}$} & & \multicolumn{2}{|c|}{$\begin{array}{c}\text { App. Long. } \\
(0.01)\end{array}$} & \multicolumn{2}{|c|}{$\begin{array}{l}\text { App. Lat. } \\
(0,01)\end{array}$} & \multicolumn{2}{|c|}{$\begin{array}{l}\text { Hor. Par. } \\
(0.0001)\end{array}$} \\
\hline & & $n$ & $\%$ & $n$ & $\%$ & $n$ & $\%$ \\
\hline $\begin{array}{r}-1 \\
0 \\
+1\end{array}$ & 1973 & $\begin{array}{r}15 \\
674 \\
41\end{array}$ & $\begin{array}{r}2.1 \\
92.3 \\
5.6\end{array}$ & $\begin{array}{r}57 \\
600 \\
73\end{array}$ & $\begin{array}{r}7.8 \\
82.2 \\
10.0\end{array}$ & $\begin{array}{r}6 \\
699 \\
25\end{array}$ & $\begin{array}{r}0.8 \\
95.7 \\
3.4\end{array}$ \\
\hline $\begin{array}{r}-1 \\
0 \\
+1\end{array}$ & 1974 & $\begin{array}{r}23 \\
679 \\
28\end{array}$ & $\begin{array}{r}3.2 \\
93.0 \\
3.8\end{array}$ & $\begin{array}{r}87 \\
545 \\
98\end{array}$ & $\begin{array}{l}11.9 \\
74.7 \\
13.4\end{array}$ & $\begin{array}{r}12 \\
705 \\
13\end{array}$ & $\begin{array}{r}1.6 \\
96.6 \\
1.8\end{array}$ \\
\hline $\begin{array}{r}-1 \\
0 \\
+1\end{array}$ & 1975 & $\begin{array}{r}44 \\
681 \\
5\end{array}$ & $\begin{array}{r}6.0 \\
93.3 \\
0.7\end{array}$ & $\begin{array}{r}91 \\
524 \\
115\end{array}$ & $\begin{array}{l}12.5 \\
71.8 \\
15.8\end{array}$ & $\begin{array}{r}25 \\
674 \\
31\end{array}$ & $\begin{array}{r}3.4 \\
92.3 \\
4.2\end{array}$ \\
\hline $\begin{array}{r}-1 \\
0 \\
+1\end{array}$ & 1976 & $\begin{array}{r}42 \\
683 \\
7\end{array}$ & $\begin{array}{r}5.7 \\
93.3 \\
1.0\end{array}$ & $\begin{array}{l}123 \\
491 \\
118\end{array}$ & $\begin{array}{l}16.8 \\
67.1 \\
16.1\end{array}$ & $\begin{array}{r}13 \\
695 \\
24\end{array}$ & $\begin{array}{r}1.8 \\
94.9 \\
3.3\end{array}$ \\
\hline $\begin{array}{r}-1 \\
0 \\
+1\end{array}$ & 1977 & $\begin{array}{r}22 \\
692 \\
16\end{array}$ & $\begin{array}{r}3.0 \\
94.8 \\
2.2\end{array}$ & $\begin{array}{r}105 \\
534 \\
91\end{array}$ & $\begin{array}{l}14.4 \\
73.2 \\
12.5\end{array}$ & $\begin{array}{r}4 \\
691 \\
35\end{array}$ & $\begin{array}{r}0.5 \\
94.7 \\
4.8\end{array}$ \\
\hline $\begin{array}{r}-1 \\
0 \\
+1\end{array}$ & 1978 & $\begin{array}{r}5 \\
675 \\
50\end{array}$ & $\begin{array}{r}0.7 \\
92.5 \\
6.8\end{array}$ & $\begin{array}{r}81 \\
566 \\
83\end{array}$ & $\begin{array}{l}11.1 \\
77.5 \\
11.4\end{array}$ & $\begin{array}{r}12 \\
693 \\
25\end{array}$ & $\begin{array}{r}1.6 \\
94.9 \\
3.4\end{array}$ \\
\hline $\begin{array}{r}-1 \\
0 \\
+1\end{array}$ & 1979 & $\begin{array}{r}3 \\
657 \\
70\end{array}$ & $\begin{array}{r}0.4 \\
90.0 \\
9.6\end{array}$ & $\begin{array}{r}52 \\
633 \\
45\end{array}$ & $\begin{array}{r}7.1 \\
86.7 \\
6.2\end{array}$ & $\begin{array}{r}11 \\
685 \\
34\end{array}$ & $\begin{array}{r}1.5 \\
93.8 \\
4.7\end{array}$ \\
\hline $\begin{array}{r}-1 \\
0 \\
+1\end{array}$ & 1980 & $\begin{array}{r}1 \\
645 \\
86\end{array}$ & $\begin{array}{r}0.1 \\
88.1 \\
11.7\end{array}$ & $\begin{array}{r}17 \\
696 \\
19\end{array}$ & $\begin{array}{r}2.3 \\
95.1 \\
2.6\end{array}$ & $\begin{array}{r}9 \\
702 \\
21\end{array}$ & $\begin{array}{r}1.2 \\
95.9 \\
2.9\end{array}$ \\
\hline $\begin{array}{r}-1 \\
0 \\
+1\end{array}$ & $1973 \sim 1980$ & $\begin{array}{r}155 \\
5386 \\
303\end{array}$ & $\begin{array}{r}2.7 \\
92.2 \\
5.2\end{array}$ & $\begin{array}{r}613 \\
4589 \\
642\end{array}$ & $\begin{array}{l}10.5 \\
78.5 \\
11.0\end{array}$ & $\begin{array}{r}92 \\
5544 \\
208\end{array}$ & $\begin{array}{r}1.6 \\
94.9 \\
3.6\end{array}$ \\
\hline
\end{tabular}


the A.E. are around $\pm 0 " 0010$ for the longitude, \pm 0 " 003 for the latitude and \pm 0 "00006 for the horizontal parallax.

\section{Nutations}

Programs for the nutations are based on Woolard's (1953) formulas. The JHDdata have been compared with the USNAO-data incorporated in the FLE. Discrepancies USNAO - JHD are less than $\pm 0 " 000003$ in the longitude and $\pm 0 " 000001$ in the obliquity. On the other hand, about $30 \%$ of the A.E.-data differ from the JHD-data by \pm 1 at the printed last decimals, 0.001 , both in the longitude and obliquity. These discrepancies may be attributed to the simplification adopted in the A.E.calculation scheme as explained by Wilkins (1954).

\section{Concluding remarks}

The discrepancies in the ephemerides between the A.E. and the TAO/JHD surveyed above might be regarded as permissible in the past. However, we can nowadays compute the ephemerides as precisely as we want by making use of computer whenever the basic theory is rigidly provided. The agreement in the Moon's ephemerides between the USNAO and the JHD is its good example. On the other hand, it may be practically difficult to compute the data which are exactly identical with those printed in the A.E. If computer programs will be constructed strictly in accordance with the basis of Newcomb's Tables of the Sun supplemented by the description in Section 2.2 of the present paper, anybody may be able to compute the ephemerides of the Sun which are exactly identical with the JHD/TAO-ephemerides as far as the soft- and hard-wares of computer permit.

It has been announced (e.g. Seidelmann, 1979) that the A.E. for the years of 1984 onwards will be provided both in printed style and on machine readable form to which a rewritten explanation with a glossary of terms used in the computation will be attached. With the general availability of computers, many A.E.-users inside and and outside of astronomy have become to want to calculate the ephemeris data by themselves instead of copying the A.E.-data. In such cases, the figures in the international ephemerides are used to examine their own programs. Accordingly the data in the international ephemerides are required to be strictly in accordance with the basic theories by far than the past. Hence, we consider that the new international ephemerides should be computed by at least two institutes independently. using different types of computer, and that the explanation attached to the ephemerides should be described sufficiently in detail so that anybody can compute the ephemeris data which exactly agree with those in the international ephemerides by the appropriate use of computer. It may be slso useful for the program check by the users to provide the ephemerides and some intermediate data, such as the values of the arguments, for sample dates covering a long interval of time, regardless to the actual accuracy of the figures as ephemerides, for example, for the beginnings of every century from B.C. 10000 to A.D. 10000.

The authors are greatly indebted to Messers. K. Onodera and S. Hutinoue, Astronomical Division of Hydrographic Department, for their assistance in the computa- 
tion and data comparison.

\section{References}

Brouwer, D., Clemence, G.M. 1961: Method of Celestial Mechanics, Academic Press, New York. Brown, E.W. 1919: Tables of the Motion of the Moon, Yale Univ. Press, New Haven.

Clemence, G.M. 1943 : Astr. J. 50, 127.

Clemence, G.M. 1954 : Astr. Pap. Amer. Eph. Vol. XIII, Pt. V.

Duncombe, R.L. 1969 : Astr. Pap. Amer. Eph. Vol. XX, Pt. II.

Eckert, W.J., Brouwer, D., Clemence, G.M. 1951: Astr. Pap. Amer. Eph. Vol. XII.

Eckert, W.J., Jones, R., Clark, H.K. 1954 : Improved Lunar Ephemeris 1952-1959, U.S. Gov. Printing Off, Washington, D.C.

Eckert, W.J., Walker, M.J', Eckert, D. 1966 : Astr. J. 71, 314.

H.M. Nautical Almanac Office and U.S. Nautical Almanac Office, 1974: Explanatory Supplement to the Astronomical Ephemeris and the American Ephemeris and Nautical Almanac, 3rd imp.

Herget, P. 1962: Astr. Pap. Amer. Eph. Vol. XVI, Pt. III.

Hill, G.W. 1895 : Astr. Pap. Amer. Eph. Vol. VII, Pt. I.

Inoue, K. 1977 : Rep. Hydrogr. Res. No. 12, p. 60.

Kinoshita, H., Nakai, H., Aoki, Sh. 1974: Ann. Tokyo Astr. Obs., 2 nd Ser. Vol. XIV, No. 1.

LeVerrier, U.-J, 1856: Ann. Obs. Paris, Tome 2.

LeVerrier, U.-J. 1858: Ann. Obs, Paris, Tome 4.

Newcomb, S. 1891: Astr. Pap. Amer. Eph. Vol. III, Pt. V.

Newcomb, S. 1895a: The Elements of the Four Inner Planets and the Fundamental Constants of Astronomy (called Astronomical Constants), Gov. Printing Off., Washington, D.C.

Newcomb, S. 1895b: Astr. Pap. Amer. Eph. Vol. VI, Pt. I.

Newcomb, S. 1895 c: Astr. Pap. Amer. Eph. Vol. VI, Pt. II.

Newcomb, S. 1895d: Astr. Pap. Amer. Eph. Vol. VI, Pt. III.

Newcomb, S. 1898 : Astr. Pap. Amer. Eph. Vol. VI, Pt. IV.

Ross, F.E. 1917: Astr. Pap. Amer. Eph. Vol. IX, Pt. II.

Seidelmann, P.K. 1979 : Dynamics of the Solar System, Proc. IAU Symposium No. 81, Ed. R.L. Duncombe, D. Reidel Pub. Co., Dordrecht.

Van Flandern, T.C. 1976 : private communication.

Wilkins, G.A. 1954: Improved Lunar Ephemeris (cited above), p. 420.

Wilkins, G.A. 1974 : private communication.

Williams, K.P., Clemence, G.M. 1942 : Astr. J. 50, 15.

Woolard, E.W. 1953: Astr. Pap. Amer. Eph. Vol. XV, Pt. I. 